\title{
Novel Quinazolinone Inhibitors of ALK2 Flip between Alternate Binding Modes: Structure-Activity Relationship, Structural Characterization, Kinase Profiling, and Cellular Proof of Concept
}

Liam Hudson, ${ }^{\S}$ James Mui, ${ }^{\S}$ Santiago Vázquez, ${ }^{\dagger}$ Diana M. Carvalho, ${ }^{\S}$ Eleanor Williams, ${ }^{\ddagger}$ Chris Jones, ${ }^{\S}$ Alex N. Bullock, and Swen Hoelder, ${ }^{*}{ }^{\ddagger}$ (i)

${ }^{\S}$ Institute of Cancer Research, 15 Cotswold Road, Sutton, Surrey SM2 5NG, United Kingdom

${ }^{\ddagger}$ Structural Genomics Consortium, University of Oxford, Old Road Campus Research Building, Roosevelt Drive, Oxford OX3 7DQ, United Kingdom

${ }^{\dagger}$ Laboratori de Química Farmacèutica (Unitat Associada al CSIC), Facultat de Farmàcia i Ciències de l'Alimentació, and Institute of Biomedicine (IBUB), Universitat de Barcelona, Av. Joan XXIII s/n, Barcelona E-08028, Spain

Supporting Information

ABSTRACT: Structure-activity relationship and crystallographic data revealed that quinazolinone-containing fragments flip between two distinct modes of binding to activin receptorlike kinase-2 (ALK2). We explored both binding modes to discover potent inhibitors and characterized the chemical modifications that triggered the flip in binding mode. We report kinase selectivity and demonstrate that compounds of this series modulate ALK2 in cancer cells. These inhibitors are attractive starting points for the discovery of more advanced ALK2 inhibitors.

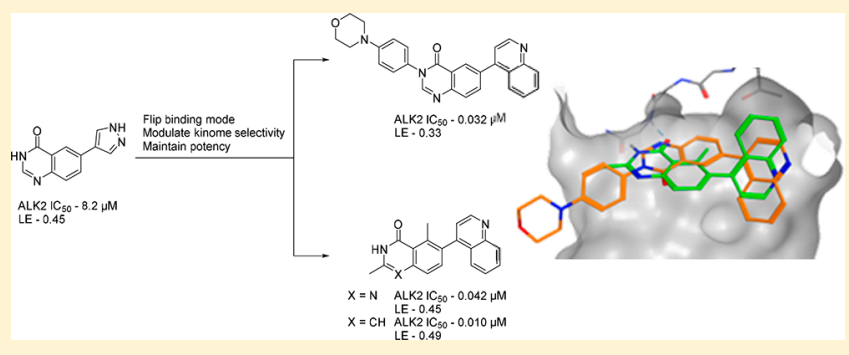

\section{INTRODUCTION}

ALK2 (gene: ACVR1) is a serine/threonine kinase in the bone morphogenetic protein (BMP) pathway and one of seven (ALK1-7) type-I receptors in the BMP and transforming growth factor beta (TGF $\beta$ ) signaling pathways. ${ }^{1}$

Signaling through ALK2 is deregulated in two disease contexts. The first is fibrodysplasia ossificans progressiva (FOP), an extremely rare condition of ectopic bone formation resulting in a progressive loss of mobility. ${ }^{2}$ Heterozygous missense mutations in ACVR1 (most commonly R206H) lead to neofunction in response to activin $\mathrm{A}$ as well as increased BMP signaling through SMAD1/5/8-the driving force in FOP. ${ }^{3}$ The second disease is diffuse intrinsic pontine glioma (DIPG), a highly infiltrative tumor originating in the pons of the brainstem. ${ }^{4}$ DIPGs arise with a peak age of incidence of 67 years and have a fatality of $100 \%$; median survival is $9-12$ months. ${ }^{4}$ As DIPGs grow diffusely throughout the vital midline brain region, surgical resection is generally considered impossible, and the current treatment of radiotherapy, while providing short-term relief of symptoms, does not prevent rapid disease progression. ${ }^{5}$

ACVR1 mutations are observed in $24 \%$ of DIPG patients. ${ }^{4}$ These mutations occur in the cytoplasmic domains of ALK2 and modulate kinase activity though (i) destabilizing the inactive conformation of the kinase and (ii) disrupting the binding of a negative regulator protein, FKBP12. ${ }^{2}$ The high frequency of ALK2 mutations in DIPG strongly suggests a contribution to disease phenotype.
ALK2 inhibitors have been reported and fall into two series (Figure 1). The first contains a pyrazolo[1,5-a]pyrimidine core and derives from dorsomorphin. Dorsomorphin was initially reported as an adenosine monophosphate (AMP)-activated

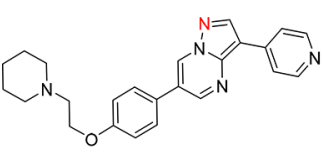

Dorsomorphin<smiles>c1ccc2c(-c3cnn4cc(-c5ccc(N6CCNCC6)cc5)cnc34)ccnc2c1</smiles>

LDN-193189

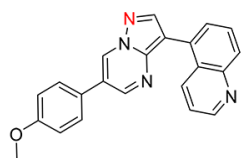

ML347

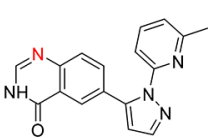

PF-03671148

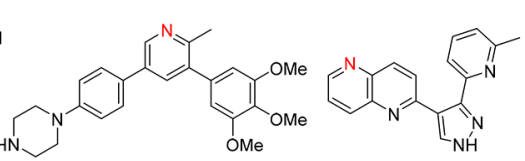

LDN-214117

Compound 19

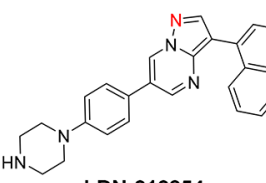

LDN-212854

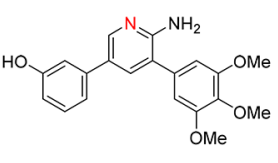

K02288

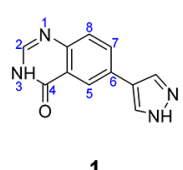

Figure 1. A selection of ALK2 and ALK5 inhibitors (the atom marked in red is the main anchor point to the kinase hinge residues).

Received: May 16, 2018

Published: August 7, 2018 
protein kinase inhibitor, but was found in a zebrafish embryo dorsalization assay to selectively inhibit BMP signaling through SMAD $1 / 5 / 8$. $^{6}$ Further development led to LDN-193189,? LDN-212854, ${ }^{8}$ and ML347, ${ }^{9}$ which had improved microsomal stability, potency, and selectivity. In addition, these molecules demonstrated efficacy in mouse models of FOP. ${ }^{8}$ However, these compounds have a number of kinase off-targets and display dose-limiting toxicity with a $10 \%$ loss in body weight in animal models. ${ }^{10} \mathrm{~A}$ second series of inhibitor based on a pyridine core (e.g., K02288 ${ }^{11}$ and LDN-214117 ${ }^{12}$ ), with equivalent biochemical potency and improved kinome selectivity, has also been reported (Figure 1).

\section{RESULTS}

We identified 6-pyrazole quinazolinone, 1, as a ligand efficient inhibitor of ALK2 $\left(\mathrm{IC}_{50}=8.2 \mu \mathrm{M}\right.$; $\left.\mathrm{LE}=0.45\right)$ through crossscreening of a focused kinase fragment library, using Invitrogen's LanthaScreen binding assay. 1 shares features with reported ALK5 inhibitors such as PF-03671148 ${ }^{13}$ and compound 19. ${ }^{14}$ These are known to bind to the hinge of ALK5 through a single polar contact at the $N-1$ position of the quinazolinone moiety, with the 2-methylpyridine directing toward the ALK5 Ser280 gatekeeper residue, forming a key water mediated hydrogen bond to Lys232 (Figure 2). ${ }^{14}$

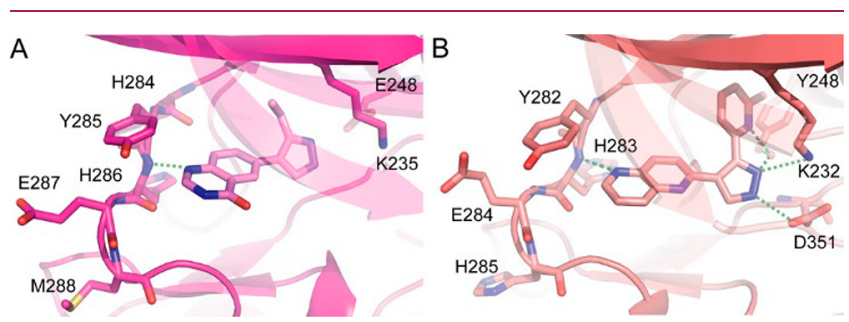

Figure 2. (A) Docking pose of 4 in ALK2 (structure used: 3Q4U). (B) X-ray structure of analogous naphthyridine-based inhibitor (compound 19) of $\mathrm{ALK5}^{14}$ (PDB 1VJY).

Interestingly, PF-03671148 has been shown to be selective against ALK1 likely due a larger gate keeper (Thr) causing a clash with the pyridine substituent. ${ }^{13}$ Given that ALK2 also features a threonine gatekeeper residue (Thr283), it is also unlikely to be potently inhibited by PF-03671148.

Unfortunately, attempts to solve the structure of 1 bound to ALK2 were not successful. However, since 1 did not feature the pyridine substituent of the published ALK5 inhibitor (compound 19), we initially hypothesized that it explored a similar binding mode when binding to ALK5 (Figure 2).

We sought to investigate whether quinazolinone 1 could be optimized into an independent series of ALK2 inhibitor and characterize its binding mode.

We started our investigations at the quinazolinone 6position, by modifying the pyrazole moiety (Table 1 ). $\mathrm{N}$ Methylation of pyrazole (2) had a minor negative effect on ALK2 binding affinity, whereas substitution at the pyrazole 3position was tolerated. Interestingly, increasing the size from methyl to cyclopropyl (4) was not only tolerated but led to a 21-fold potency increase. A 3,5-dimethylpyrazole (6) maintained sub- $\mu \mathrm{M}$ potency and was the most efficiently binding pyrazole derivative with an impressive LE of 0.51 . This initial set of compounds, particularly compounds $\mathbf{2}$ and $\mathbf{6}$, suggested that the pyrazole was not the hinge binding motif and instead binds to Lys235 through a water bridge, as observed for compound 19 in Figures 1 and 2. This prompted us to replace
Table 1. SAR at Quinazolinone 6-Position ${ }^{a}$

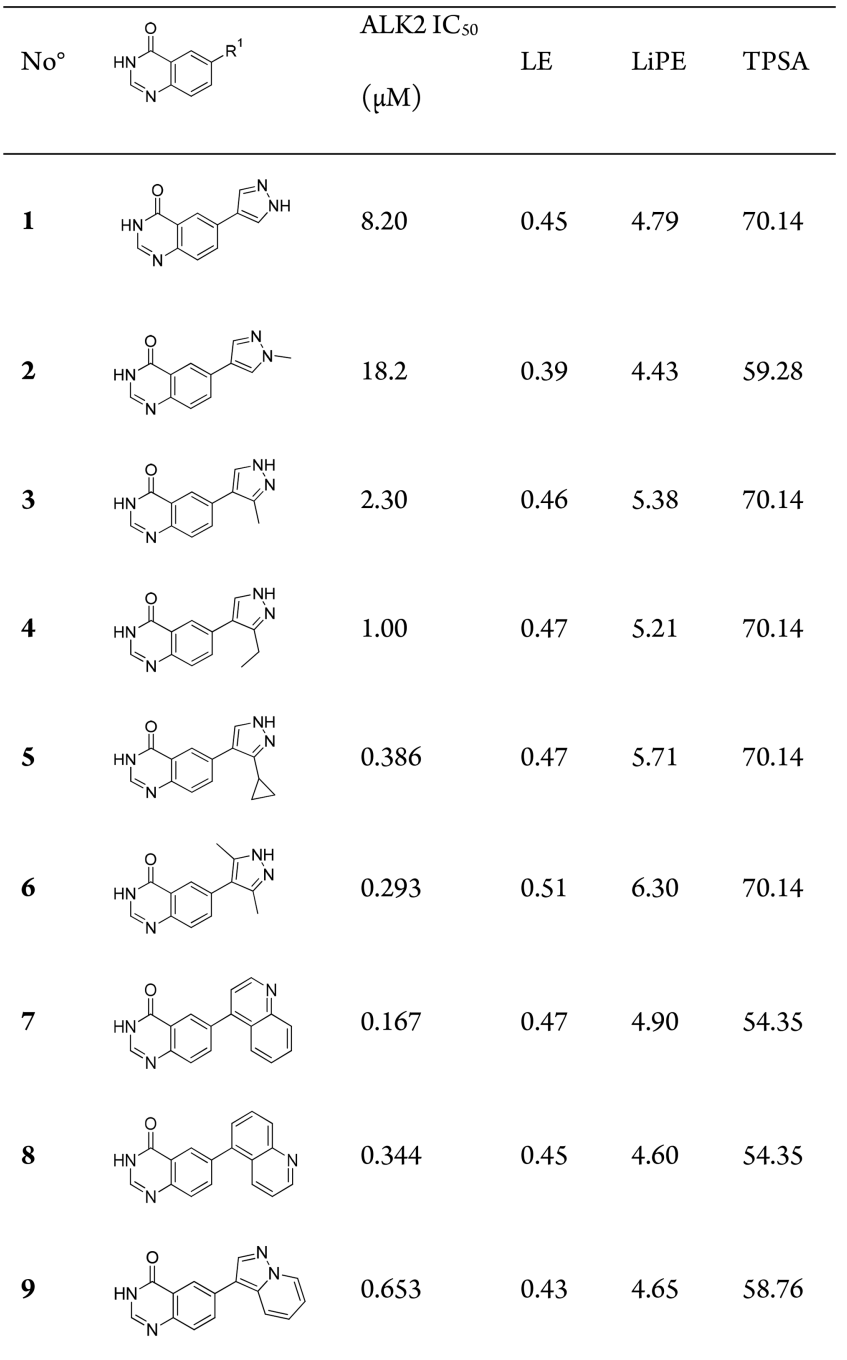

${ }^{a} \mathrm{IC}_{50}$ data is an average of $2-4$ measurements by LanthaScreen Eu kinase binding assay.

the pyrazole for a bicycle (7-9). Since DIPG requires brain penetrable drugs, this had the added benefit of reducing the TPSA, a well-established predictor for passive permeability across the blood-brain barrier. ${ }^{15}$ Gratifyingly, this afforded a 40-80-fold improvement in potency over the initial hit. As the 4- and 5-quinoline examples (7 and 8) represented the most promising compounds so far, with sub- $\mu \mathrm{M}$ potency, good ligand efficiency and low TPSA, we decided to focus further modification on these isomers.

On the basis of the observed structure-activity relationship (SAR), we hypothesized that the compounds presented in Table 1 adopted a binding mode in which the variable heteroaromatic group occupied the ALK2 central pocket, extending toward the catalytic lysine (Lys235), similarly to reported ALK5 inhibitors (Figure 2). ${ }^{14}$ We also expected that this binding mode would be preserved between the pyrazoles and quinolines, which are present in several reported ALK2 inhibitors (Figure 1). However, it was still not clear how the quinazolinone core interacted with the hinge region. In an effort to shed light on this question, we positioned a methyl group at various positions around the quinazolinone ring (Table 2). 
Table 2. Quinazolinone Methyl Scan $\operatorname{SAR}^{a}$

\begin{tabular}{|c|c|c|c|c|}
\hline & ALK2 & & & \\
\hline $\mathrm{No}^{\circ}$ & $\mathrm{IC}_{50}(\mu \mathrm{M})$ & LE & LiPE & TPSA \\
\hline 10 & 0.220 & 0.42 & 4.39 & 54.35 \\
\hline 11 & 0.194 & 0.43 & 4.43 & 54.35 \\
\hline 12 & 0.186 & 0.43 & 4.32 & 45.56 \\
\hline 13 & 0.383 & 0.42 & 4.12 & 45.56 \\
\hline 14 & 0.248 & 0.42 & 4.06 & 54.35 \\
\hline 15 & 0.138 & 0.44 & 4.38 & 54.35 \\
\hline
\end{tabular}

${ }^{a} \mathrm{IC}_{50}$ data is an average of $2-4$ measurements by LanthaScreen Eu kinase binding assay.

When compared to the desmethyl analogues (7 and 8), a 5methyl group (10 and 11) did not alter potency. This was consistent with the binding mode suggested in Figure 2, where the additional methyl group would direct toward solvent. 3Methyl isomers 12 and 13 were also of equivalent potency, which again was consistent with a binding mode as in Figure 2 where the 3-methyl directs toward the solvent channel of ALK2. Surprisingly, analogous 2-methyl isomers (14 and 15) also displayed equal potency at ALK2. This was an unexpected result given that a 2-position substituent should clash with protein under the proposed binding model.

While this surprising tolerance to substitution at all three positions (Table 2 ) did not clearly suggest a preferred hinge binding motif, the 3-methyl isomer 12 stood out due to the low TPSA and closest analogy to published inhibitors. ${ }^{7}$

We decided to explore further substitution at the quinazolinone 3-position and incorporated solvent channel groups that had led to activity gains in other series, e.g., the pyrazolo $[1,5-a]$ pyrimidine series. Introduction of a 4-morpholinophenyl group (16) was found to increase the potency 5fold (Table 3 ) and yielded the most potent compound up to this point. However, the additional 12 heavy atoms from the 4morpholinophenyl group did inflict a 0.11-0.19 LE unit penalty, suggesting that the solvent channel group was suboptimal.

To understand why only modest potency gains were afforded a series of truncated and modified analogues were prepared: phenyl (17), cyclohexyl (18), 3-morpholinopropyl (19), and 4-dimethyl aniline (20). Comparison of these analogues showed that the phenyl ring alone leads to a loss of activity compared to the methyl derivative, 12. Replacement by a cyclohexyl group did not drastically reduce binding further, suggesting that saturated or otherwise three-dimensional groups may be tolerated in this region of the ALK2 pocket.
Table 3. SAR at Quinazolinone 3-Position ${ }^{a}$

\begin{tabular}{|c|c|c|c|c|}
\hline $\mathrm{No}^{\circ}$ & ALK2 & $\mathrm{LE}$ & LiPE & TPSA \\
\hline 16 & 0.032 & 0.33 & 3.57 & 58.03 \\
\hline 17 & 0.431 & 0.32 & 1.75 & 45.56 \\
\hline 18 & 1.525 & 0.31 & 1.45 & 45.56 \\
\hline 19 & 0.165 & 0.32 & 3.90 & 58.03 \\
\hline 20 & 0.068 & 0.33 & 2.35 & 48.80 \\
\hline
\end{tabular}

${ }^{a} \mathrm{IC}_{50}$ data is an average of $2-4$ measurements by LanthaScreen Eu kinase binding assay.

The 30-fold gain in potency achieved through the addition of morpholine (16) to phenyl-only compound 17 suggests that the phenyl ring is acting as a linker for this polar function. However, a simple propyl linker (19) to the morpholine unit does not afford a similar potency boost. In addition, maintaining the phenyl ring, but removing the ether functionality [of 16], leaving a dimethyl aniline (20) had a negligible effect on binding-strongly suggesting that the amine, and its precise position, are key to achieving potent inhibitors of ALK2.

With more potent compounds in hand, we reattempted cocrystallization and indeed managed to obtain the cocrystal structure of 16 with ALK2 to 2.2 A resolution (Figure 3). The compound indeed displayed a binding mode similar to the reported inhibitor LDN-193189-quinazolinone $N$-1 interacts as an HBA for the ALK2 hinge residue His286, the 4morpholino phenyl group directs through the solvent channel, and the 4-quinoline occupies the central pocket, with the quinoline- $N$-atom forming a water-bridged interaction to Lys235. Other similarities between the solved structure of $\mathbf{1 6}$ and LDN-193189 include the variable position of morpholine and methylpiperidine in the solvent channel-multiple conformations exist for both compounds in their respective asymmetric units suggesting that while the phenyl-bonded $\mathrm{N}$ atoms may have a significant role in binding the distal N-Me/ $\mathrm{O}$ atom is unlikely to contribute heavily. We can only speculate on the reason why the morpholine amine contributes so strongly to binding. It is unlikely that this amine is charged due to the aniline character and electron withdrawing ether function. However, upon inspection of the electron density map for $\mathbf{1 6}$ a water bridged hydrogen bond to V214 is visible in one ALK2 chain in the asymmetric unit and may contribute to the gain in potency (Figure 3A). A notable difference versus available structures of pyrazolo[1,5-a]pyrimidine-based ALK2 inhibitors (PDB 3Q4U) is that the central pocket quinoline penetrates deeper toward Lys235 (Figure 3B), by virtue of the larger hinge-binding core. 
A

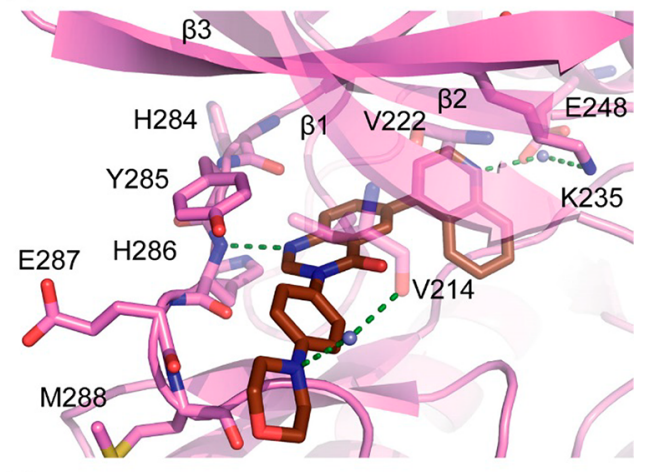

B

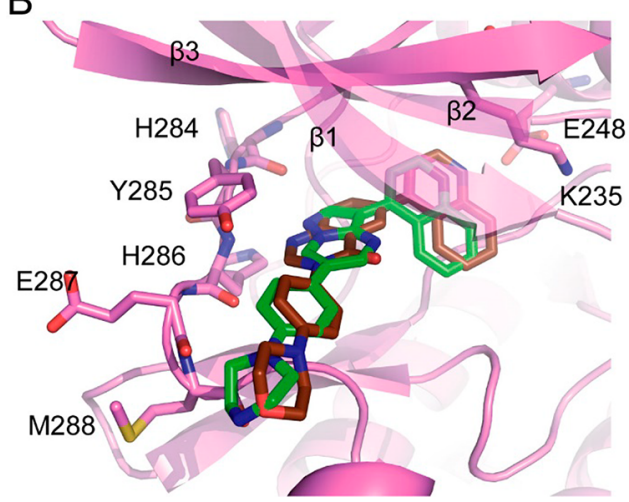

Figure 3. (A) Cocrystal structure of $\mathbf{1 6}$ in ALK2 showing three Hbond acceptors for H286, K235, and V214 (PDB 6GIN). (B) Overlay of 16 (brown) with LDN-193189 (green, PDB 3Q4U) showing deeper penetrance of 4-quinoline toward K235 for 16, and slight change in position of the solvent channel group.

The binding mode revealed by the crystal structure was consistent with our earlier hypothesis of preferred binding mode (cf. Figure 2 with the key hinge binding interaction between the quinazolinone $\mathrm{N}-1$ and His286). An interesting observation was that some compounds (e.g., 14 and 15) maintained potency even though the additional 2-methylation would likely cause a clash with the hinge residues of ALK2 suggesting that they bind through an alternate binding mode. We therefore sought to solve additional structures and were able to obtain the structure of compound 11. Interestingly, 11 displayed a flipped binding mode (Figure 4A) in which the quinazolinone core bound to His286 through the amide, as a donor and acceptor. This also altered the vector from the quinazolinone 6-position such that the quinoline also flipped in order to fill the same volume in the ALK2 central pocket as for 16 (Figure 4B).

Inspection of the compound bound in the flipped binding mode (11) suggested that introduction of small hydrophobic groups in the 2-position should not only be tolerated but would lead to additional hydrophobic interaction (Table 4). Interestingly, while introduction of the 2- and 5-methyl groups individually (Table 2) was tolerated but did not lead to an increase in activity, introduction of both (21) afforded a 6-fold increase in potency (Table 4). We hypothesized that this cooperative increase in potency can be explained by the change in binding mode: 2-methylation forces adoption of the flipped, and presumably lower preference binding mode [for unsubstituted quinazolinones] (Figure 4C); however, there is no change in potency due to the addition of a methyl group in a relatively nonpolar part of the binding pocket. 5-Methylation

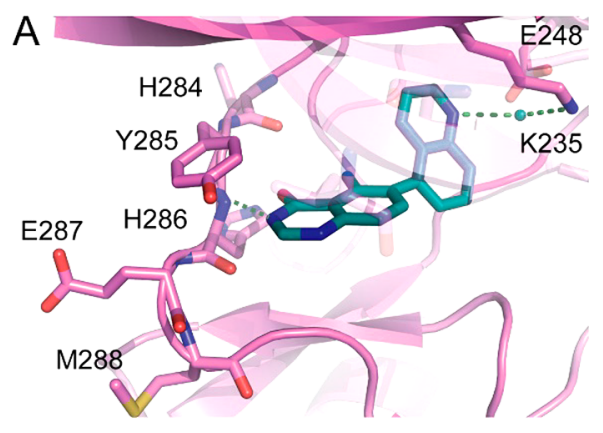

B

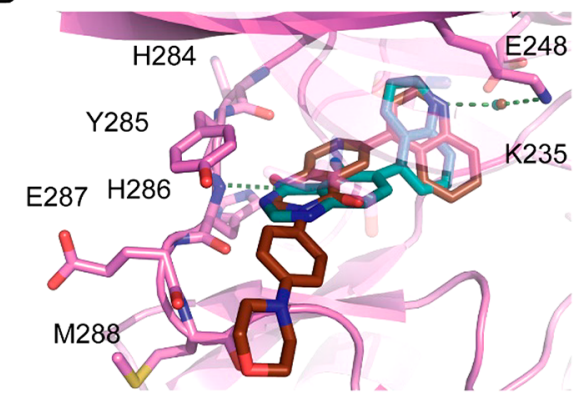

C

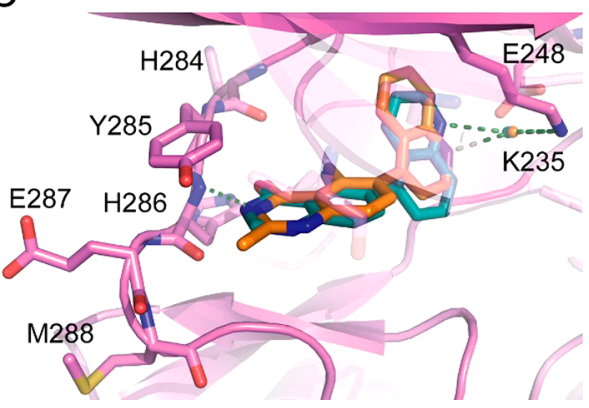

Figure 4. (A) Cocrystal structure of 11 with ALK2 (PDB 6GI6). (B) Superposition of costructures of $\mathbf{1 1}$ (blue) and $\mathbf{1 6}$ (brown). (C) Superposition of the costructures of $\mathbf{1 1}$ (blue) and $\mathbf{2 1}$ (orange, PDB 6GIP).

Table 4. SAR of Flipped Binding Series ${ }^{a}$

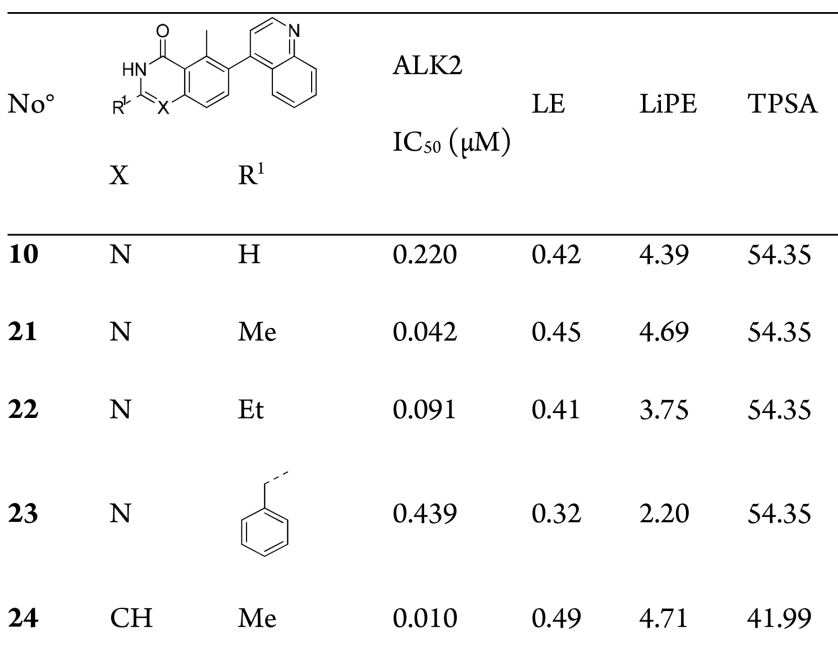

${ }^{a} \mathrm{IC}_{50}$ data is an average of $2-4$ measurements by LanthaScreen Eu Kinase Binding Assay.

fills the excluded volume created by flipping binding mode, which in the absence of 2-methylation is apparently enough to 
compensate for adopting the less energetically favored flipped binding mode. Once the flipped mode is induced by one methyl substituent, addition of the second does not incur a further penalty and reaps the benefit of the newly formed interaction.

To assess the available space at the quinazolinone 2-position of the inhibitors binding in the flipped binding mode, we designed and prepared a few additional compounds. Crystallography suggested that the 2-methyl group could be replaced by larger groups. This was indeed the case. Increasing the size of the 2-substitutent to ethyl (22) or benzyl (23) was tolerated but did lead to a modest reduction in potencymirroring the phenyl-only compound for the precedented binding mode (13), suggesting that there is scope to further investigate substituents at this position.

Furthermore, as the flipped binders do not appear to make use of $N-1$ for interaction with ALK2, we hypothesized that replacement with a $\mathrm{C}$ atom would result in additional hydrophobic interaction and loss of the desolvation penalty upon binding due to the polar heteroatom. The resulting isoquinolinone 24 indeed displayed $10 \mathrm{nM}$ potency with a superb LE of 0.49 .

At this stage, two divergent series with quinazolinone cores were developed to the stage of a having potency $<50 \mathrm{nM}$. We hypothesized that inhibitors of the normal and flipped modes would display distinct selectivity profiles. To test this hypothesis, the most potent normal and flipped binding quinazolinones (16 and 21 respectively) were assessed in DiscoveRx's scanEDGE panel of 97 diverse kinases, plus all reported off-targets of the pyrazolo[1,5-a]pyrimidine and pyridine series (Table S1). . $^{8,9,1}$

Both quinazolinone based inhibitors displayed excellent selectivity in the kinome panel tested, though some notable differences were evident (Figure 5). At $1 \mu \mathrm{M}$ the normal binder, 16, showed similarly potent inhibition of ALK6, platelet-derived growth factor receptor (PDGFR) A and B and Proto-Oncogene receptor tyrosine kinase KIT. While the flipped binder, 21, showed selectivity confined to the tyrosine kinase-like (TKL) family of kinases-a surprising result given its low molecular weight. Aside from the highly homologous ALKs 1, 4, 5, and 6, RAF1 and BRAF were also inhibited by 21. These results indicate that the two different compounds have distinct inhibition profiles within the kinome, versus each other as well as reported inhibitors and that both have a highly encouraging level of selectivity against the panel of kinases screened.

$K_{\mathrm{D}}$ values were obtained for ALKs $1-6$ and all off-targets identified in Figure 5, for both 16 and 21 (Table 5) using DiscoverX's $K_{\mathrm{d}}$ ELECT assay. 16 had similar affinity for ALKs 1, 2, 3, and 6 (which all signal through SMADs 1, 5, and 8) with moderate selectivity over ALKs 4 and 5 (which signal through SMADs 2 and 3 ). This profile is similar to reported ALK2 inhibitors. ${ }^{8,9,12}$ The smaller, flipped binder, 21, displayed an atypical profile-with lower selectivity over ALKs 4 and 5 and considerable variance in affinity for ALKs 1, 2, 3, and 6. The fact that 21 binds ALKs 1 and 6 16-fold more potently than ALK2 shows that $\mathbf{2 1}$ is not yet favorable for FOP and DIPG which harbor various activating mutations in ALK2. However, this is the first case, to our knowledge, of a small molecule with ALK1 selectivity over ALK2, which shares $79 \%$ sequence identity in their kinase domains. ${ }^{11}$ This is a potentially useful property if developed further to investigate

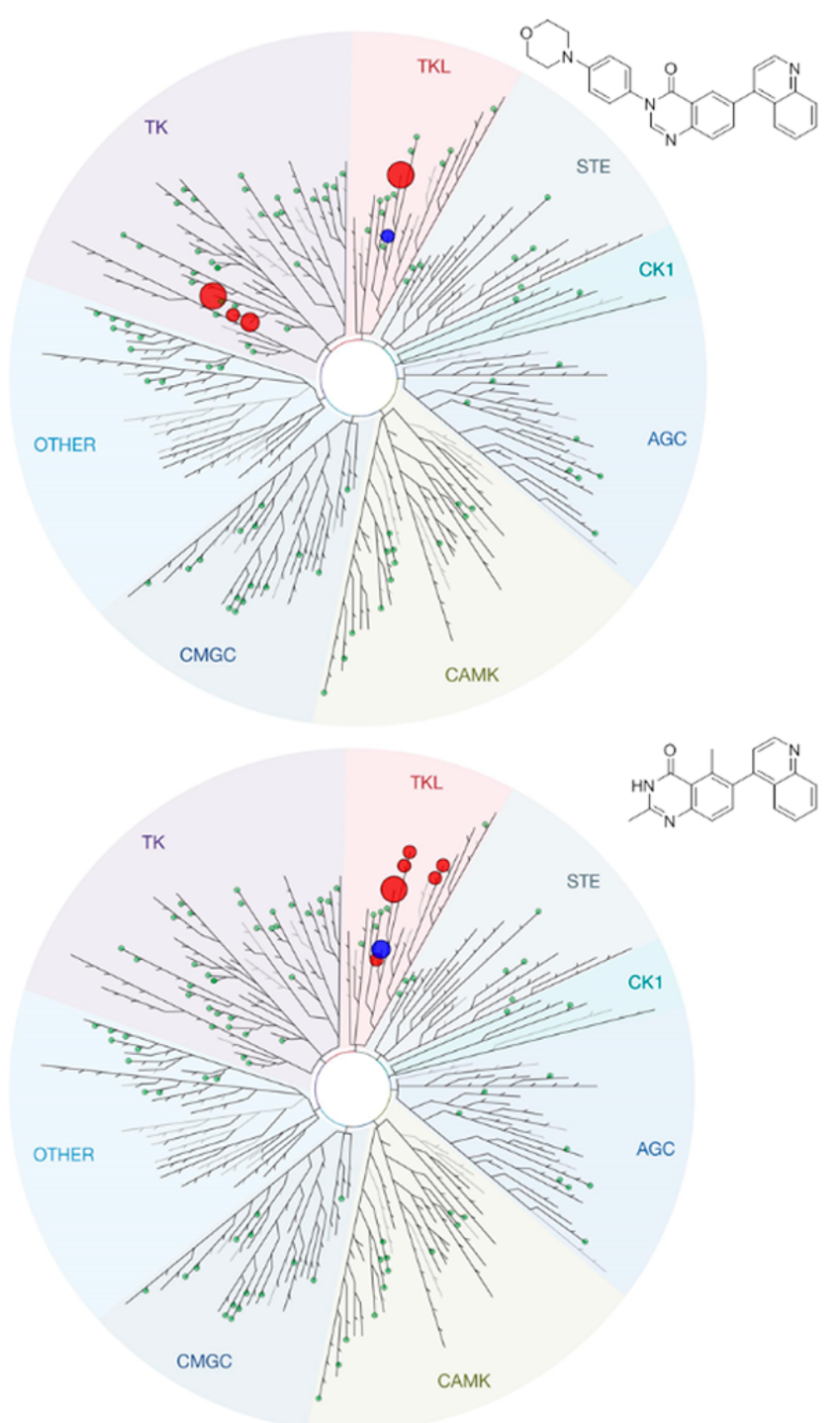

Figure 5. Kinase selectivity profile of 16 and 21 at $1 \mu \mathrm{M}$. Blue circle ALK2; Green circles $\leq 65 \%$ probe displacement; small red circle $=$ $65-90 \%$ probe displacement; intermediate circle $=90-95 \%$ probe displacement; larger red circle $=95-99 \%$ probe displacement.

Table 5. $K_{\mathrm{D}}$ 's for ALKs $1-6$ and All off-Targets Identified for Compounds 16 and $21^{a}$

\begin{tabular}{lll} 
& \multicolumn{2}{c}{$K_{\mathrm{D}}(\mathrm{nM})$} \\
\cline { 2 - 3 } kinase & $\mathbf{1 6}$ & $\mathbf{2 1}$ \\
ALK1 & 420 & 41 \\
ALK2 & 330 & 640 \\
ALK3 & 610 & 2700 \\
ALK4 & 11000 & 690 \\
ALK5 & 19000 & 1000 \\
ALK6 & 96 & 39 \\
BRAF & & 65 \\
RAF1 & & 330 \\
KIT & 54 & \\
PDGRFA & 43 & \\
PDGRFB & 250 &
\end{tabular}

${ }^{a} K_{\mathrm{D}}$ 's calculated from duplicate 11-point dose-response curves; KdELECT, DiscoverX 
the role of ALK1 in various disease contexts, particularly in regulating angiogenesis. ${ }^{16}$

Finally, to achieve proof of concept that this class of compound shows activity in cells, we tested if $\mathbf{2 4}$ modulates the BMP pathway downstream of ALK2 (Figure 6) in HSJD-

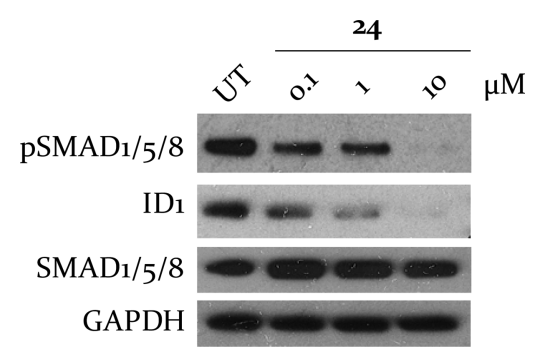

Figure 6. Dose-dependent reduction in markers of ALK2 inhibition in HSJD-DIPG7 cells.

DIPG-007 patient derived cells (H3F3A K27M and ACVR1 $\mathrm{R} 206 \mathrm{H})$ at three different concentrations $(0.1 \mu \mathrm{M}, 1 \mu \mathrm{M}$, and $10 \mu \mathrm{M})$. Encouragingly, 24 displayed a dose-dependent reduction of pSMAD1/5/8 and ID1.

Compounds were prepared principally by a multicomponent reaction between orthoesters, amines, and anthranillic acids, followed by a Suzuki coupling (Scheme 1). For non-

Scheme 1. General Route to Quinazolinone Derivatives ${ }^{a}$

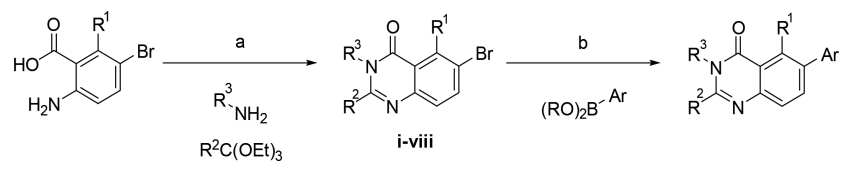

${ }^{a}$ (a) $110{ }^{\circ} \mathrm{C}, 16-100 \%$; (b) $\mathrm{PdCl}_{2}\left(\mathrm{PPh}_{3}\right)_{2}, \mathrm{NaOH}(\mathrm{aq})$, 1,4-dioxane, $120-150{ }^{\circ} \mathrm{C}, 12-100 \%$.

commercially available pyrazole boronic acids/esters, the parent pyrazole was brominated, then tosyl-protected $(\mathbf{i x}-\mathbf{x})$, which allowed for a one-pot borylation and Suzuki protocol.

2-Benzyl quinazolinones were prepared by treatment of benzylcyanide with hydroxylamine, forming an intermediate amidoxime (Scheme 2). ${ }^{17}$ In the same pot, reaction with anthranillic acid, 25, afforded 6-bromo intermediate 26, which was functionalized by Suzuki coupling.

Scheme 2. Synthesis of 2-Benzyl Quinazolinones ${ }^{a}$

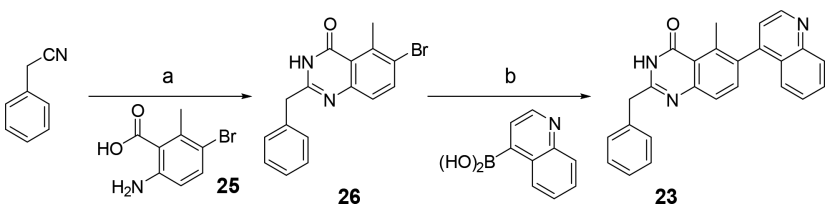

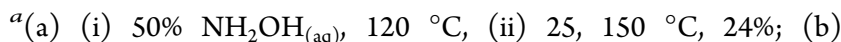
$\mathrm{PdCl}_{2}\left(\mathrm{PPh}_{3}\right)_{2}, \mathrm{NaOH}_{(\mathrm{aq})}, 1,4$-dioxane, $100{ }^{\circ} \mathrm{C}, 51-100 \%$.

Isoquinolinones were prepared by a Doebner-modified Knoevenagel condensation with 4-bromo-3-methylbenzaldehyde, leading to 27 (Scheme 3). ${ }^{18}$ Preparation of a mixed anhydride with ethyl chloroformate followed by treatment with sodium azide gave $\mathbf{2 8}$, and subsequent Curtius rearrangement allowed for intramolecular trapping of the isocyanate to yield a 3:2 mixture of isoquinolinone regioisomers (29 and 30). After
Scheme 3. Synthesis of Isoquinolinones ${ }^{a}$

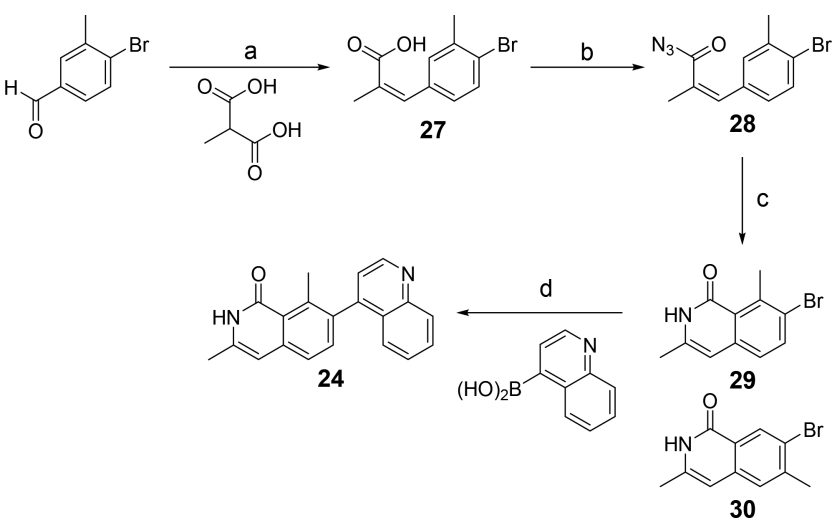

a (a) Piperidine, $110{ }^{\circ} \mathrm{C}, 64 \%$; (b) (i) $\mathrm{NEt}_{3}$, acetone, ethyl chloroformate, $0{ }^{\circ} \mathrm{C}-\mathrm{RT}$; (ii) $\mathrm{NaN}_{3}$, water, RT, 97\%; (c) $\mathrm{I}_{2}, 1,2$ dichlorobenzene, $140-180{ }^{\circ} \mathrm{C}, 50 \%$ [3:2] 29:30; (d) $\mathrm{PdCl}_{2}\left(\mathrm{PPh}_{3}\right)_{2}$, $\mathrm{Na}_{2} \mathrm{CO}_{3(\mathrm{aq})}, 1,4$-dioxane, $150{ }^{\circ} \mathrm{C}, 61 \%$.

chromatographic separation, the major product (29) was functionalized by a Suzuki coupling.

\section{DISCUSSION AND CONCLUSIONS}

In conclusion, we identified a ligand efficient quinazolinone fragment (1) for inhibition of the ALK2 kinase domain through systematic cross screening. We found that the 6pyrazole of 1 could be modified or replaced with bicyclic groups for gains in potency and that the activity was surprisingly tolerant to addition of methyl groups at the quinazolinone 2-, 3-, and 5-positions. Guided by crystallography, we were able to rationalize this tolerance through a flipped binding mode. We explored both binding modes to discover potent inhibitors. Our work shows that there is scope for further investigation of the SAR of both series and that the kinome selectivity profiles for example compounds (16 and 21) are not only distinct from one another but also do not hit off-targets for previously reported ALK2 inhibitors at the concentration tested. Finally we demonstrated that compound 24 modulates ALK2 in cells in a dose-dependent manner.

The compounds presented here thus represent attractive starting points to discover potent and selective inhibitors of activin receptor-like kinases.

\section{EXPERIMENTAL SECTION}

Unless otherwise stated, commercially available reagents and solvents were used without further purification. Yields were not optimized. NMR experiments were performed on a BrukerAvance $500 \mathrm{MHz}$ spectrometer using an internal deuterium lock. Chemical shifts were measured in parts per million (ppm) relative to the residual signal of the deuterated solvent. Data are presented in the following format: chemical shift (multiplicity $[\mathrm{s}=$ singlet, $\mathrm{d}=$ doublet, $\mathrm{t}=$ triplet, $\mathrm{q}=$ quartet, $\mathrm{p}=$ pentet, $\mathrm{m}=$ multiplet, and $\mathrm{br}=$ broad], coupling constants $(J$ in $\mathrm{Hz})$, integration). Where mixed solvent systems were used residual solvent peaks to which the spectra are referenced are underlined. Assignment of ${ }^{13} \mathrm{C}$ NMR data was achieved through analysis of 2D NMR spectra (HSQC, HMBC, COSY, and NOSEY). LCMS analyses and high resolution mass spectrometry were performed on an Agilent 1200 series HPLC and diode array detector coupled to a 6210 time-of-flight mass spectrometer with dual multimode APCI/ESI source (methods A and B) or a Waters Acquity UPLC and diode array detector coupled to a Waters G2 QToF mass spectrometer fitted with a multimode ESI/APCI source (method C); see Supporting Information for method details. All 
compounds described herein exhibited spectral data consistent with their proposed structures and, with the exception of 6 (purity $>90 \%$ ), had purities $>95 \%$ as determined by HPLC.

General Procedure 1: Multicomponent Reaction. A mixture of an anthranillic acid or isatoic anhydride (1.0 equiv), amine (1.0 equiv), and orthoester (1.0 equiv) was stirred for $1-16 \mathrm{~h}$ at $110^{\circ} \mathrm{C}$, until LCMS indicated that reaction was complete. The mixture was cooled to RT, and the product was purified either by crystallization or trituration with hot $\mathrm{EtOH}$ unless otherwise indicated.

6-Bromo-3-(4-morpholinophenyl)quinazolin-4(3H)-one, i. Following general procedure 1 , 6-bromo- $2 \mathrm{H}$-benzo $[d][1,3]$ oxazine2,4(1H)-dione ( $1.00 \mathrm{~g} ; 4.15 \mathrm{mmol} ; 1.0$ equiv), 4-morpholinoaniline (740 mg; $4.15 \mathrm{mmol} ; 1.0$ equiv), and triethoxymethane ( $940 \mathrm{mg} ; 4.15$ mmol; 1.0 equiv) were used to yield 6-bromo-3-(4morpholinophenyl)quinazolin-4(3H)-one $(1.59 \mathrm{~g} ; 4.13 \mathrm{mmol}$; $100 \%)$ as a light purple solid. ${ }^{1} \mathrm{H}$ NMR $\left(500 \mathrm{MHz}, \mathrm{CDCl}_{3}\right) \delta 8.41$ $(\mathrm{d}, J=2.3 \mathrm{~Hz}, 1 \mathrm{H}), 8.08(\mathrm{~s}, 1 \mathrm{H}), 7.84(\mathrm{dd}, J=8.6,2.3 \mathrm{~Hz}, 1 \mathrm{H}), 7.59$ $(\mathrm{d}, J=8.6 \mathrm{~Hz}, 1 \mathrm{H}), 7.26-7.23(\mathrm{~m}, 2 \mathrm{H}), 7.00-6.97(\mathrm{~m}, 2 \mathrm{H}), 3.86-$ $3.82(\mathrm{~m}, 4 \mathrm{H}), 3.21-3.18(\mathrm{~m}, 4 \mathrm{H}) .{ }^{13} \mathrm{C}$ NMR $\left(126 \mathrm{MHz}, \mathrm{CDCl}_{3}\right) \delta$ $160.07,151.65,147.00,146.44,137.80,129.57,129.04,128.43$, $127.52,123.54,121.30,115.86,66.64,48.63$. HRMS (ESI) $\mathrm{m} / z$ calc $\mathrm{C}_{18} \mathrm{H}_{17} \mathrm{BrN}_{3} \mathrm{O}_{2}[\mathrm{M}+\mathrm{H}]^{+}$386.0499; found = 386.0501 .

6-Bromo-3-phenylquinazolin-4(3H)-one, ii. 6-Bromo- $2 \mathrm{H}$ benzo[d][1,3] oxazine-2,4(1H)-dione $(1.00 \mathrm{~g} ; 4.15 \mathrm{mmol} ; 1.0$ equiv), aniline ( $379 \mu \mathrm{L} ; 4.15 \mathrm{mmol} ; 1.0$ equiv), and triethoxymethane (615 mg; $4.15 \mathrm{mmol} ; 1.0$ equiv) were stirred at $110^{\circ} \mathrm{C}$ for $18 \mathrm{~h}$. The resulting tar was loaded onto silica with $\mathrm{CH}_{2} \mathrm{Cl}_{2}$ and purified by column chromatography in a solvent system of $0-5 \% \mathrm{MeOH}$ in $\mathrm{CH}_{2} \mathrm{Cl}_{2}$. 6-Bromo-3-phenylquinazolin-4(3H)-one (387 mg; 1.29 mmol; $31 \%)$ was obtained as a beige solid. ${ }^{1} \mathrm{H}$ NMR $(500 \mathrm{MHz}$, $\left.\mathrm{CDCl}_{3}\right) \delta 8.51(\mathrm{~d}, J=2.2 \mathrm{~Hz}, 1 \mathrm{H}), 8.15(\mathrm{~s}, 1 \mathrm{H}), 7.90(\mathrm{dd}, J=8.7,2.3$ $\mathrm{Hz}, 1 \mathrm{H}), 7.66(\mathrm{~d}, J=8.6 \mathrm{~Hz}, 1 \mathrm{H}), 7.60-7.56(\mathrm{~m}, 2 \mathrm{H}), 7.55-7.51(\mathrm{~m}$, $1 \mathrm{H}), 7.45-7.42(\mathrm{~m}, 2 \mathrm{H}) .{ }^{13} \mathrm{C} \mathrm{NMR}\left(126 \mathrm{MHz}, \mathrm{CDCl}_{3}\right) \delta 159.61$, $146.75,146.41,137.79,137.19,129.76,129.74,129.43,129.34$, $126.91,123.79,121.34$. HRMS (ESI) $m / z$ calc $\mathrm{C}_{14} \mathrm{H}_{10} \mathrm{BrN}_{2} \mathrm{O}[\mathrm{M}+$ $\mathrm{H}]^{+}$300.9971; found $=300.9977$.

6-Bromo-3-cyclohexylquinazolin-4(3H)-one, iii. 6-Bromo- $2 \mathrm{H}$ benzo[ $d][1,3]$ oxazine-2,4(1H)-dione ( $1.00 \mathrm{~g} ; 4.15 \mathrm{mmol} ; 1.0$ equiv), cyclohexanamine $(475 \mu \mathrm{L} ; 4.15 \mathrm{mmol} ; 1.0$ equiv) and triethoxymethane (615 mg; $4.15 \mathrm{mmol} ; 1.0$ equiv) were stirred at $110^{\circ} \mathrm{C}$ for $18 \mathrm{~h}$. The resulting tar was loaded onto silica with $\mathrm{CH}_{2} \mathrm{Cl}_{2}$ and purified by column chromatography in a solvent system of $0-5 \%$ $\mathrm{MeOH}$ in $\mathrm{CH}_{2} \mathrm{Cl}_{2}$. 6-Bromo-3-phenylquinazolin-4(3H)-one $(429 \mathrm{mg}$; $1.40 \mathrm{mmol} ; 34 \%)$ was obtained as a light yellow solid. ${ }^{1} \mathrm{H}$ NMR (500 $\left.\mathrm{MHz}, \mathrm{CDCl}_{3}\right) \delta 8.45(\mathrm{~d}, J=2.2 \mathrm{~Hz}, 1 \mathrm{H}), 8.13(\mathrm{~s}, 1 \mathrm{H}), 7.83(\mathrm{dd}, J=$ 8.7, $2.3 \mathrm{~Hz}, 1 \mathrm{H}), 7.58(\mathrm{~d}, J=8.7 \mathrm{~Hz}, 1 \mathrm{H}), 4.81(\mathrm{tt}, J=12.3,3.7 \mathrm{~Hz}$, $1 \mathrm{H}), 2.05-1.99(\mathrm{~m}, 2 \mathrm{H}), 1.99-1.93(\mathrm{~m}, 2 \mathrm{H}), 1.81$ (ddtd, $J=14.7$, $4.9,3.2,1.4 \mathrm{~Hz}, 1 \mathrm{H}), 1.71-1.59(\mathrm{~m}, 2 \mathrm{H}), 1.54(\mathrm{qt}, J=13.2,3.3 \mathrm{~Hz}$, $2 \mathrm{H}), 1.28(\mathrm{qt}, J=13.0,3.7 \mathrm{~Hz}, 1 \mathrm{H}) \cdot{ }^{13} \mathrm{C}$ NMR $\left(126 \mathrm{MHz}, \mathrm{CDCl}_{3}\right) \delta$ $159.55,146.38,144.22,137.29,129.52,129.11,123.33,120.68,53.65$, $32.58,25.86,25.24$. HRMS (ESI) $m / z$ calc $\mathrm{C}_{14} \mathrm{H}_{16} \mathrm{BrN}_{2} \mathrm{O}[\mathrm{M}+\mathrm{H}]^{+}$ 307.0441 ; found $=307.0448$.

6-Bromo-3-(3-morpholinopropyl)quinazolin-4(3H)-one, iv. 6-Bromo-2H-benzo[d][1,3] oxazine-2,4(1H)-dione (1.0 g; 4.15 mmol; 1.0 equiv), 3-morpholinopropan-1-amine (598 mg; 4.15 mmol; 1.0 equiv), and triethoxymethane $(940 \mathrm{mg} ; 6.35 \mathrm{mmol} ; 1.5$ equiv) were stirred at $110{ }^{\circ} \mathrm{C}$ for $5 \mathrm{~h}$. The resulting tar was loaded onto silica with $\mathrm{CH}_{2} \mathrm{Cl}_{2}$ and purified by column chromatography in a solvent system of $0-8 \% \mathrm{MeOH}$ in $\mathrm{CH}_{2} \mathrm{Cl}_{2}$ to yield 6-bromo-3-(3morpholinopropyl)quinazolin-4(3H)-one (1.06 g; $3.02 \mathrm{mmol}$; $73 \%)$ as a yellow oil. ${ }^{1} \mathrm{H}$ NMR (500 MHz, DMSO) $\delta 8.43(\mathrm{~s}, 1 \mathrm{H}), 8.22(\mathrm{~d}$, $J=2.4 \mathrm{~Hz}, 1 \mathrm{H}), 7.96(\mathrm{dd}, J=8.7,2.4 \mathrm{~Hz}, 1 \mathrm{H}), 7.63(\mathrm{~d}, J=8.7 \mathrm{~Hz}$, $1 \mathrm{H}), 4.02(\mathrm{t}, J=6.9 \mathrm{~Hz}, 2 \mathrm{H}), 3.44(\mathrm{t}, J=4.7 \mathrm{~Hz}, 4 \mathrm{H}), 2.31(\mathrm{t}, J=6.6$ $\mathrm{Hz}, 2 \mathrm{H}), 2.27$ (br-s, 4H), $1.86(\mathrm{p}, J=6.7 \mathrm{~Hz}, 2 \mathrm{H}) .{ }^{13} \mathrm{C}$ NMR $(126$ $\mathrm{MHz}, \mathrm{DMSO}) \delta 159.68,149.44,147.48,137.47,130.02,128.52$, $123.66,119.77,66.52,55.58,53.50,45.53,24.79$. HRMS (ESI) $\mathrm{m} / z$ calc $\mathrm{C}_{15} \mathrm{H}_{19} \mathrm{BrN}_{3} \mathrm{O}_{2}[\mathrm{M}+\mathrm{H}]^{+} 352.0655$; found $=352.0636$.

6-Bromo-3-(4-(dimethylamino)phenyl)quinazolin-4(3H)one, v. Following general procedure 1 , 6-bromo- $2 H$-benzo $[d][1,3]$ oxazine-2,4(1H)-dione (1.0 g; $4.15 \mathrm{mmol} ; 1.0$ equiv), $N^{1}, N^{1}$ - dimethylbenzene-1,4-diamine ( $565 \mathrm{mg} ; 4.15 \mathrm{mmol} ; 1.0$ equiv), and triethoxymethane ( $615 \mathrm{mg} ; 4.15 \mathrm{mmol} ; 1.0$ equiv) were used to yield 6-bromo-3-(4-(dimethylamino)phenyl)quinazolin-4(3H)-one (833 $\mathrm{mg} ; 2.43 \mathrm{mmol}$; 59\%) as a glittery, dark-purple solid. ${ }^{1} \mathrm{H}$ NMR $\left(500 \mathrm{MHz}, \mathrm{CDCl}_{3}\right) \delta 8.50(\mathrm{~d}, J=2.3 \mathrm{~Hz}, 1 \mathrm{H}), 8.14(\mathrm{~s}, 1 \mathrm{H}), 7.87(\mathrm{dd}$, $J=8.7,2.3 \mathrm{~Hz}, 1 \mathrm{H}), 7.64(\mathrm{~d}, J=8.6 \mathrm{~Hz}, 1 \mathrm{H}), 7.26-7.22(\mathrm{~m}, 2 \mathrm{H})$, 6.84-6.79 (m, 2H), $3.04(\mathrm{~s}, 6 \mathrm{H}) .{ }^{13} \mathrm{C} \mathrm{NMR}\left(126 \mathrm{MHz}, \mathrm{CDCl}_{3}\right) \delta$ $160.13,150.74,147.30,146.84,137.46,129.70,129.30,127.41$, $125.62,123.88,120.99$, 112.49, 40.46. HRMS (ESI) $m / z$ calc $\mathrm{C}_{16} \mathrm{H}_{15} \mathrm{BrN}_{3} \mathrm{O}[\mathrm{M}+\mathrm{H}]^{+}$344.0393; found $=344.0403$.

6-Bromo-2-methylquinazolin-4(3H)-one, vi. 6-Bromo- $2 \mathrm{H}$ benzo $[d][1,3]$ oxazine-2,4(1H)-dione $(1.00 \mathrm{~g} ; 4.15 \mathrm{mmol} ; 1.0$ equiv), $\mathrm{NH}_{4} \mathrm{OAc}$ ( $385 \mathrm{mg} ; 5.00 \mathrm{mmol} ; 1.2$ equiv), and triethoxymethane (673 mg; $4.15 \mathrm{mmol} ; 1.0$ equiv) were stirred at $110{ }^{\circ} \mathrm{C}$ for $18 \mathrm{~h}$. The crude reaction product was loaded onto silica using $\mathrm{CH}_{2} \mathrm{Cl}_{2}$ and purified by column chromatography with a solvent system of $0-$ $8 \% \mathrm{MeOH}$ in $\mathrm{CH}_{2} \mathrm{Cl}_{2}$ 6-Bromo-2-methylquinazolin-4(3H)-one $(212$ $\mathrm{mg}$; $0.891 \mathrm{mmol} ; 21 \%)$ was isolated as a cream solid. ${ }^{1} \mathrm{H}$ NMR (500 $\left.\mathrm{MHz}, \underline{\mathrm{CDCl}_{3}} / \mathrm{MeOH}\right) \delta 8.28(\mathrm{~d}, J=2.3 \mathrm{~Hz}, 1 \mathrm{H}), 7.76(\mathrm{dd}, J=8.7$, $2.4 \mathrm{~Hz}, 1 \mathrm{H}), 7.45(\mathrm{~d}, J=8.7 \mathrm{~Hz}, 1 \mathrm{H}), 2.40(\mathrm{~s}, 3 \mathrm{H}) .{ }^{13} \mathrm{C}$ NMR $(126$ $\left.\mathrm{MHz}, \mathrm{CDCl}_{3} / \mathrm{MeOH}\right) \delta 161.87,154.36,147.56,137.82,128.72$, $128.20,121.88,119.82$, 21.36. HRMS (ESI) $m / z$ calc $\mathrm{C}_{9} \mathrm{H}_{8} \mathrm{BrN}_{2} \mathrm{O}[\mathrm{M}$ $+\mathrm{H}]^{+}$238.9815; found $=238.9822$.

6-Bromo-2,5-dimethylquinazolin-4(3H)-one, vii. 6-Amino-3bromo-2-methylbenzoic acid (950 mg; $4.15 \mathrm{mmol} ; 1.0$ equiv), $\mathrm{NH}_{4} \mathrm{OAc}(385 \mathrm{mg} ; 5.00 \mathrm{mmol} ; 1.2$ equiv) and triethoxymethane (673 mg; $4.15 \mathrm{mmol}$; 1.0 equiv) were stirred at $110{ }^{\circ} \mathrm{C}$ for $48 \mathrm{~h}$. The crude reaction product was loaded onto silica using $\mathrm{CH}_{2} \mathrm{Cl}_{2}$ and purified by column chromatography with a solvent system of $0-8 \%$ $\mathrm{MeOH}$ in $\mathrm{CH}_{2} \mathrm{Cl}_{2}$. 6-Bromo-2,5-dimethylquinazolin-4(3H)-one $(255$ $\mathrm{mg} ; 1.01 \mathrm{mmol}$; $24 \%)$ was isolated as a cream solid. ${ }^{1} \mathrm{H}$ NMR (500 $\left.\mathrm{MHz}, \underline{\mathrm{CDCl}_{3}} / \mathrm{MeOH}\right) \delta 7.77(\mathrm{dd}, J=8.8,1.5 \mathrm{~Hz}, 1 \mathrm{H}), 7.25(\mathrm{~d}, J=$ $8.3 \mathrm{~Hz}, 1 \mathrm{H}), 2.90(\mathrm{~s}, 3 \mathrm{H}), 2.33(\mathrm{~s}, 3 \mathrm{H}) .{ }^{13} \mathrm{C} \mathrm{NMR}(126 \mathrm{MHz}$, $\left.\mathrm{CDCl}_{3} / \mathrm{MeOH}\right) \delta 166.76,157.95,153.44,143.71,142.04,129.43$, $127.89,124.22,25.22,24.73$. HRMS (ESI) $\mathrm{m} / z$ calc $\mathrm{C} 10 \mathrm{H} 10 \mathrm{BrN} 2 \mathrm{O}$ $[\mathrm{M}+\mathrm{H}]+252.9971$; found $=252.9980$.

6-Bromo-2-ethyl-5-methylquinazolin-4(3H)-one, viii. 6Amino-3-bromo-2-methylbenzoic acid (950 mg; $4.15 \mathrm{mmol} ; 1.0$ equiv), $\mathrm{NH}_{4} \mathrm{OAc}(385 \mathrm{mg} ; 5.00 \mathrm{mmol} ; 1.2$ equiv), and triethyl orthopropionate (731 mg; $4.15 \mathrm{mmol}$; 1.0 equiv) were stirred at 110 ${ }^{\circ} \mathrm{C}$ for $48 \mathrm{~h}$. The crude reaction product was loaded onto silica using $\mathrm{CH}_{2} \mathrm{Cl}_{2}$ and purified by column chromatography with a solvent system of $0-8 \% \mathrm{MeOH}$ in $\mathrm{CH}_{2} \mathrm{Cl}_{2}$. 6-Bromo-2-ethyl-5-methylquinazolin-4(3H)-one $(418 \mathrm{mg} ; 1.57 \mathrm{mmol} ; 38 \%)$ was isolated as an offwhite solid. ${ }^{1} \mathrm{H}$ NMR (500 MHz, DMSO) $\delta 12.17$ (s, 1H), 7.91 (d, $J$ $=8.7 \mathrm{~Hz}, 1 \mathrm{H}), 7.36(\mathrm{~d}, J=8.7 \mathrm{~Hz}, 1 \mathrm{H}), 2.92(\mathrm{~s}, 3 \mathrm{H}), 2.58(\mathrm{q}, J=7.5$ $\mathrm{Hz}, 2 \mathrm{H}), 1.23(\mathrm{t}, J=7.5 \mathrm{~Hz}, 3 \mathrm{H}) .{ }^{13} \mathrm{C}$ NMR $(126 \mathrm{MHz}, \mathrm{DMSO}) \delta$ $162.45,159.18,150.45,138.98,137.79,127.17,122.94,121.18,27.87$, $21.54,11.57$. HRMS (ESI) $m / z$ calc $\mathrm{C}_{11} \mathrm{H}_{12} \mathrm{BrN}_{2} \mathrm{O}[\mathrm{M}+\mathrm{H}]^{+}$ 267.0128; found $=267.0135$.

4-Bromo-3-cyclopropyl-1-tosyl-1H-pyrazole, ix. To a solution of 4-bromo-3-cyclopropyl-1 $\mathrm{H}$-pyrazole $(100 \mathrm{mg} ; 0.538 \mathrm{mmol} ; 1.0$ equiv) in $\mathrm{CH}_{2} \mathrm{Cl}_{2}(10 \mathrm{~mL} ; 0.054 \mathrm{M})$ was added $\mathrm{NaOH}_{(\mathrm{aq})}(118 \mu \mathrm{L} ; 5$ $\mathrm{M} ; 0.591 \mathrm{mmol}$; 1.1 equiv) and 4-toluenesulfonyl chloride (113 mg; $0.591 \mathrm{mmol} ; 1.1$ equiv). The mixture was heated to reflux and stirred for $72 \mathrm{~h}$ before being diluted with water $(400 \mathrm{~mL})$ and extracted with $\mathrm{CH}_{2} \mathrm{Cl}_{2}(2 \times 200 \mathrm{~mL})$. The combined organic portions were washed with brine, dried $\left(\mathrm{Na}_{2} \mathrm{SO}_{4}\right)$, and filtered, and solvent was removed under reduced pressure. The crude product was washed through an SCX-II column with $\mathrm{MeOH}$ to yield 4-bromo-3-cyclopropyl-1-tosyl$1 \mathrm{H}$-pyrazole (103 mg; $0.303 \mathrm{mmol} ; 56 \%$ ) as a white solid after removal of solvent under reduced pressure. ${ }^{1} \mathrm{H}$ NMR $(500 \mathrm{MHz}$, DMSO) $\delta 8.68(\mathrm{~s}, 1 \mathrm{H}), 7.86-7.81(\mathrm{~m}, 2 \mathrm{H}), 7.48(\mathrm{~d}, J=8.1 \mathrm{~Hz}, 2 \mathrm{H})$, $2.40(\mathrm{~s}, 3 \mathrm{H}), 1.84(\mathrm{tt}, J=8.3,4.9 \mathrm{~Hz}, 1 \mathrm{H}), 0.99-0.93(\mathrm{~m}, 2 \mathrm{H}), 0.78-$ $0.73(\mathrm{~m}, 2 \mathrm{H}) .{ }^{13} \mathrm{C}$ NMR (126 MHz, DMSO) $\delta$ 158.61, 146.80, $133.46,133.17,130.88,128.12,99.30,21.64,8.83,7.76$. HRMS (ESI) $m / z$ calc $\mathrm{C}_{13} \mathrm{H}_{13} \mathrm{BrN}_{2} \mathrm{O}_{2} \mathrm{SNa}[\mathrm{M}+\mathrm{Na}]^{+} 362.9779$; found $=362.9771$.

4-Bromo-3-ethyl-1-tosyl-1H-pyrazole, x. $p$-Toluene sulfonyl chloride (194 mg; $1.02 \mathrm{mmol}$; 1.1 equiv) was added to a solution of 4-bromo-3-ethyl-1H-pyrazole (162 mg; $0.930 \mathrm{mmol} ; 1.0$ equiv) and 
[5 M] $\mathrm{NaOH}$ solution $\left(0.2 \mathrm{~mL} ; 1.02 \mathrm{mmol} ; 1.1\right.$ equiv) in $\mathrm{CH}_{2} \mathrm{Cl}_{2}$ $(18.5 \mathrm{~mL})$, and the mixture was stirred at $38{ }^{\circ} \mathrm{C}$. After $16 \mathrm{~h}$ the reaction mixture was washed with water $(15 \mathrm{~mL})$ and the aqueous layer was extracted with $\mathrm{CH}_{2} \mathrm{Cl}_{2}(2 \times 20 \mathrm{~mL})$. The combined organic fractions were washed with brine, dried over $\mathrm{MgSO}_{4}$, filtered, and concentrated under vacuum. The crude mixture was purified by normal phase flash chromatography in a solvent system of $0-5 \%$ EtOAc in cyclohexane to afford 4-bromo-3-ethyl-1-tosyl- $1 \mathrm{H}$-pyrazole (246 mg; $0.826 \mathrm{mmol} ; 81 \%$ ) as a white solid. ${ }^{1} \mathrm{H}$ NMR (500 MHz, $\left.\mathrm{CDCl}_{3}\right) \delta 8.03(\mathrm{~s}, 1 \mathrm{H}), 7.85-7.93(\mathrm{~m}, 2 \mathrm{H}), 7.30-7.38(\mathrm{~m}, 2 \mathrm{H}), 2.62$ $(\mathrm{q}, J=7.6,2 \mathrm{H}), 2.44(\mathrm{~s}, 3 \mathrm{H}), 1.22(\mathrm{t}, J=7.6,3 \mathrm{H}) .{ }^{13} \mathrm{C}$ NMR $(126$ $\left.\mathrm{MHz}_{\mathrm{CDCl}}\right) \delta 158.69,145.92,133.86,128.13,98.52,21.74,20.38$, 12.23. HRMS (ESI) $m / z$ calc $\mathrm{C}_{12} \mathrm{H}_{14} \mathrm{BrN}_{2} \mathrm{O}_{2} \mathrm{~S}[\mathrm{M}+\mathrm{H}]^{+}$328.9954; found $=328.9954$.

General Procedure 2: Suzuki Coupling. To a Biotage microwave vial was added the required bromo-aryl (1.0 equiv), boronic acid or ester (1.0-1.2 equiv), $\mathrm{PdCl}_{2}\left(\mathrm{PPh}_{3}\right)_{2}$ (0.05 equiv), $\mathrm{Na}_{2} \mathrm{CO}_{3(\mathrm{aq})}$ (0.5 M; 1.0 equiv), and 1,4-dioxane or DME. The vial was sealed and purged of air with 3 rounds of vacuum and $\mathrm{N}_{2}$ or Ar. The mixture was heated to $120-150{ }^{\circ} \mathrm{C}$ for $1 \mathrm{~h}$ under microwave irradiation. The reaction mixture was filtered through Celite, washed with water, and extracted twice with $\mathrm{CH}_{2} \mathrm{Cl}_{2}$. Combined organic portions were dried $\left(\mathrm{Na}_{2} \mathrm{SO}_{4}\right)$, filtered, and had solvent removed under reduced pressure. The crude product was purified by column chromatography in a solvent system of $\mathrm{MeOH}$ in $\mathrm{CH}_{2} \mathrm{Cl}_{2}$.

6-(1H-Pyrazol-4-yl)quinazolin-4(3H)-one, 1. Following general procedure 2, 6-bromoquinazolin- $4(3 \mathrm{H})$-one $(44 \mathrm{mg} ; 0.20 \mathrm{mmol})$ was reacted with [1-(tert-butoxycarbonyl)-1H-pyrazol-4-yl]boronic acid pinacol ester ( $69 \mathrm{mg} ; 0.24 \mathrm{mmol})$ in DME to yield 6-( $1 \mathrm{H}$-pyrazol-4yl)quinazolin-4(3H)-one (22 mg; 54\%) as an off-white solid. Reaction temperature: $150{ }^{\circ} \mathrm{C}$. Purification: $1-8 \% \mathrm{MeOH}$ in $\mathrm{CH}_{2} \mathrm{Cl}_{2} \cdot{ }^{1} \mathrm{H}$ NMR (500 MHz, DMSO) 13.06 (br-s, 1H), 12.21 (br-s, 1H), 8.38 (br-s, $1 \mathrm{H}), 8.28(\mathrm{~d}, J=2.2 \mathrm{~Hz}, 1 \mathrm{H}), 8.08(\mathrm{dd}, J=8.4,2.2 \mathrm{~Hz}, 1 \mathrm{H})$, $8.05(\mathrm{~s}, 1 \mathrm{H}), 8.04(\mathrm{br}-\mathrm{s}, 1 \mathrm{H}), 7.65(\mathrm{~d}, J=8.4 \mathrm{~Hz}, 1 \mathrm{H}) .{ }^{13} \mathrm{C} \mathrm{NMR}$ (126 MHz, DMSO) 161.2, 147.4, 145.0, 136.9, 132.1, 128.2, 126.6, 123.5, 121.3, 120.6. HRMS (ESI) $\mathrm{m} / z$ calc $\mathrm{C}_{11} \mathrm{H}_{9} \mathrm{~N}_{4} \mathrm{O}[\mathrm{M}+\mathrm{H}]^{+}$ 213.0771; found $=213.0779$.

6-(1-Methyl-1H-pyrazol-4-yl)quinazolin-4(3H)-one, 2. Following general procedure 2, 6-bromoquinazolin-4(3H)-one $(47 \mathrm{mg}$; $0.21 \mathrm{mmol}$ ) was reacted with 1-methylpyrazole-4-boronic acid pinacol ester ( $52 \mathrm{mg} ; 0.25 \mathrm{mmol})$ in DME to yield 6-(1-methyl- $1 \mathrm{H}$-pyrazol-4yl)quinazolin- $4(3 \mathrm{H})$-one $(42 \mathrm{mg} ; 88 \%)$ as a white solid. Reaction temperature: $150{ }^{\circ} \mathrm{C}$. Purification: $1-8 \% \mathrm{MeOH}$ in $\mathrm{CH}_{2} \mathrm{Cl}_{2} \cdot{ }^{1} \mathrm{H}$ NMR (500 MHz, DMSO) 12.2 (br-s, 1H), $8.32(\mathrm{~d}, J=0.9 \mathrm{~Hz}, 1 \mathrm{H})$, $8.23(\mathrm{~d}, J=2.1 \mathrm{~Hz}, 1 \mathrm{H}), 8.04($ br-s, $1 \mathrm{H}), 8.02(\mathrm{dd}, J=8.5,2.2 \mathrm{~Hz}$, $1 \mathrm{H}), 7.99(\mathrm{~d}, J=0.9 \mathrm{~Hz}, 1 \mathrm{H}), 7.65(\mathrm{~d}, J=8.5 \mathrm{~Hz}, 1 \mathrm{H}), 3.88(\mathrm{~s}, 3 \mathrm{H})$. ${ }^{13} \mathrm{C}$ NMR (126 MHz, DMSO) 161.2, 147.4, 145.0, 136.8, 131.8, 128.9, 128.3, 123.6, 121.1, 121.1, 39.2. HRMS (ESI) $\mathrm{m} / \mathrm{z}$ calc $\mathrm{C}_{12} \mathrm{H}_{11} \mathrm{~N}_{4} \mathrm{O}[\mathrm{M}+\mathrm{H}]^{+}$227.0927; found $=227.0924$.

6-(3-Methyl-1H-pyrazol-4-yl)quinazolin-4(3H)-one, 3. Following general procedure 2, 6-bromoquinazolin-4(3H)-one $(31 \mathrm{mg}$; $0.14 \mathrm{mmol})$ was reacted with 3-methyl- $1 \mathrm{H}$-pyrazole-4-boronic acid pinacol ester (35 mg; $0.17 \mathrm{mmol})$ and $\mathrm{Pd}\left(\mathrm{PPh}_{3}\right)_{4}(11 \mathrm{mg} ; 7 \mathrm{~mol} \%)$ in DME. After $40 \mathrm{~min}$, additional 3-methyl-1H-pyrazole-4-boronic acid pinacol ester $(29 \mathrm{mg} ; 0.14 \mathrm{mmol})$ and $\mathrm{Pd}\left(\mathrm{PPh}_{3}\right)_{4}(8 \mathrm{mg} ; 0.05$ equiv) were added, and the mixture was stirred under microwave irradiation at $150{ }^{\circ} \mathrm{C}$ for $30 \mathrm{~min}$. After this time, the reaction was purified by SCX-2 chromatography $(2 \mathrm{~g}, 30 \mathrm{~mL} \mathrm{MeOH}$ then $30 \mathrm{~mL} 1$ $\mathrm{M}$ ammonia in $\mathrm{MeOH}$ ) and column chromatography (10 g SNAP, 3$9 \% \mathrm{MeOH}$ in $\mathrm{CH}_{2} \mathrm{Cl}_{2}$ ) to afford 6-(3-methyl-1H-pyrazol-4-yl)quinazolin-4(3H)-one $(14 \mathrm{mg} ; 44 \%)$ as a cream solid. ${ }^{1} \mathrm{H}$ NMR $(500 \mathrm{MHz}, \mathrm{DMSO}) \delta 12.75(\mathrm{~d}, J=41.8 \mathrm{~Hz}, 1 \mathrm{H}), 12.24(\mathrm{~s}, 1 \mathrm{H}), 8.11$ (s, $1 \mathrm{H}), 8.06(\mathrm{~d}, J=3.3 \mathrm{~Hz}, 1 \mathrm{H}), 7.94(\mathrm{dd}, J=8.3,2.2 \mathrm{~Hz}, 1 \mathrm{H}), 7.81$ $(\mathrm{s}, 1 \mathrm{H}), 7.68(\mathrm{~d}, J=8.5 \mathrm{~Hz}, 1 \mathrm{H}), 2.42(\mathrm{~d}, J=30.9 \mathrm{~Hz}, 3 \mathrm{H}) .{ }^{13} \mathrm{C}$ NMR (126 MHz, DMSO) $\delta 161.19,147.06,145.11,138.75,135.75,133.27$, $132.88,128.14,123.32,122.47,117.15,11.13$. HRMS (ESI) $m / z$ calc $\mathrm{C}_{12} \mathrm{H}_{11} \mathrm{~N}_{4} \mathrm{O}[\mathrm{M}+\mathrm{H}]^{+} 227.0927$; found $=227.0933$.

6-(3-Ethyl-1H-pyrazol-4-yl)quinazolin-4(3H)-one, 4. 4Bromo-3-ethyl-1-tosyl-1H-pyrazole (66 mg; $0.194 \mathrm{mmol}$; 1.0 equiv), KOAc ( $57 \mathrm{mg}$; $0.583 \mathrm{mmol}$; 1.1 equiv), bis(pinacolato)diboron (55 mg; 0.214 mmol; 1.1 equiv), and $\mathrm{PdCl}_{2}\left(\mathrm{PPh}_{3}\right)_{2}$ (6.8 mg; $9.70 \mu \mathrm{mol}$; 0.05 equiv) were charged to a microwave vial. The vial was sealed and purged of air with avacuum and $\mathrm{N}_{2}$ five times. 1,4-Dioxane $(4.4 \mathrm{~mL}$; $0.044 \mathrm{M}$ ) was added, and the mixture was heated at $120^{\circ} \mathrm{C}$ for $1 \mathrm{~h}$ under microwave irradiation. At RT, 6-bromoquinazolin-4(3H)-one (44 mg; 0.194 mmol; 1.0 equiv), [0.5 M] $\mathrm{Na}_{2} \mathrm{CO}_{3(\mathrm{aq})}(389 \mu \mathrm{L} ; 0.194$ mmol; 1.0 equiv), and $\mathrm{PdCl}_{2}\left(\mathrm{PPh}_{3}\right)_{2}(6.8 \mathrm{mg} ; 9.70 \mu \mathrm{mol} ; 0.05$ equiv) were added to the reaction mixture before the vial was sealed and purged of air with vacuum and $\mathrm{N}_{2}$ five times. The mixture was heated to $120^{\circ} \mathrm{C}$ for $1 \mathrm{~h}$ under microwave irradiation. The mixture was then diluted with water $(100 \mathrm{~mL})$ and extracted with $\mathrm{CH}_{2} \mathrm{Cl}_{2}(3 \times 75 \mathrm{~mL})$. Combined organic portions were washed with brine $(100 \mathrm{~mL})$, dried $\left(\mathrm{Na}_{2} \mathrm{SO}_{4}\right)$, and filtered, and solvent was removed under reduced pressure. The crude product was purified by column chromatography in a solvent system of $2-15 \% \mathrm{MeOH}$ in $\mathrm{CH}_{2} \mathrm{Cl}_{2}$ to yield 6-(3-ethyl-1tosyl-1H-pyrazol-4-yl)quinazolin-4 $(3 \mathrm{H})$-one $(13 \mathrm{mg} ; 0.03 \mathrm{mmol}$; $15 \%)$ as a white solid. A solution of the tosyl-protected intermediate was formed in $\mathrm{EtOH}(1.1 \mathrm{~mL})$, to which was added $[1 \mathrm{M}] \mathrm{NaOH}_{(\mathrm{aq})}$ $(0.8 \mathrm{~mL} ; 0.82 \mathrm{mmol})$. The mixture was stirred at $50{ }^{\circ} \mathrm{C}$ for $14 \mathrm{~h}$ and then neutralized using $1 \mathrm{M} \mathrm{HCl}$ and purified by SCX-2 chromatography $\left(2 \mathrm{~g}, 10 \mathrm{~mL} \mathrm{MeOH}\right.$ then $30 \mathrm{~mL} 1 \mathrm{M} \mathrm{NH}_{3}$ in $\mathrm{MeOH}$ ). The crude mixture was further purified by Biotage column chromatography $(5-12 \% \mathrm{MeOH}$ in DCM) and concentrated under a vacuum. The resulting solid was triturated with $n$-hexane $(3 \times 1 \mathrm{~mL})$ to afford 6-(3-ethyl-1H-pyrazol-4-yl)quinazolin-4 $(3 H)$-one $(7 \mathrm{mg}$, $0.025 \mathrm{mmol}, 82 \%)$ as an off-white solid. ${ }^{1} \mathrm{H}$ NMR $(500 \mathrm{MHz}$, DMSO) $\delta 12.77(\mathrm{~s}, 1 \mathrm{H}), 12.25(\mathrm{~s}, 1 \mathrm{H}), 8.09(\mathrm{~d}, J=2.1 \mathrm{~Hz}, 1 \mathrm{H}), 8.06$ $(\mathrm{d}, J=3.4 \mathrm{~Hz}, 1 \mathrm{H}), 7.90(\mathrm{dd}, J=8.4,2.2 \mathrm{~Hz}, 1 \mathrm{H}), 7.68(\mathrm{~d}, J=8.5 \mathrm{~Hz}$, $1 \mathrm{H}), 2.82(\mathrm{t}, J=7.6 \mathrm{~Hz}, 2 \mathrm{H}), 1.22(\mathrm{t}, J=7.6 \mathrm{~Hz}, 4 \mathrm{H}) .{ }^{13} \mathrm{C}$ NMR $(126$ $\mathrm{MHz}, \mathrm{DMSO}) \delta 161.18,147.14,145.16,133.73,132.92,128.12$, 123.32 , 122.97, 18.25, 13.86. HRMS (ESI) $m / z$ calc $\mathrm{C}_{13} \mathrm{H}_{13} \mathrm{~N}_{4} \mathrm{O}[\mathrm{M}$ $+\mathrm{H}]^{+}$241.1084; found $=241.1084$.

6-(3-Cyclopropyl-1H-pyrazol-4-yl)quinazolin-4(3H)-one, 5. 4-Bromo-3-cyclopropyl-1-tosyl-1H-pyrazole $(30 \mathrm{mg} ; 0.0882 \mathrm{mmol}$; 1.0 equiv), KOAc ( $26 \mathrm{mg} ; 0.265 \mathrm{mmol} ; 1.1$ equiv), bis(pinacolato)diboron (25 mg; $0.0971 \mathrm{mmol} ; 1.1$ equiv), and $\mathrm{PdCl}_{2}\left(\mathrm{PPh}_{3}\right)_{2}$ (3.1 mg; $4.41 \mu \mathrm{mol} ; 0.05$ equiv) were charged to a microwave vial. The vial was sealed and purged of air with a vacuum and $\mathrm{N}_{2}$ five times. 1,4Dioxane $(2 \mathrm{~mL} ; 0.044 \mathrm{M})$ was added, and the mixture was heated at $120{ }^{\circ} \mathrm{C}$ for $1 \mathrm{~h}$ under microwave irradiation. 6-Bromoquinazolin$4(3 \mathrm{H})$-one (20 mg; $0.0882 \mathrm{mmol} ; 1.0$ equiv), [0.5 M] $\mathrm{Na}_{2} \mathrm{CO}_{3(\mathrm{aq})}$ (176 $\mu \mathrm{L} ; 0.0882 \mathrm{mmol} ; 1.0$ equiv), and $\mathrm{PdCl}_{2}\left(\mathrm{PPh}_{3}\right)_{2}(3.1 \mathrm{mg} ; 4.41$ $\mu$ mol; 0.05 equiv) were added to the reaction mixture $\left(<40{ }^{\circ} \mathrm{C}\right)$ before the vial was sealed and purged of air with a vacuum and $\mathrm{N}_{2}$ five times. The mixture was heated to $120{ }^{\circ} \mathrm{C}$ for $1 \mathrm{~h}$ under microwave irradiation. The mixture was diluted with water $(100 \mathrm{~mL})$ and extracted with $\mathrm{CH}_{2} \mathrm{Cl}_{2}(3 \times 75 \mathrm{~mL})$. The combined organic portions were washed with brine $(100 \mathrm{~mL})$, dried $\left(\mathrm{Na}_{2} \mathrm{SO}_{4}\right)$ and filtered and solvent was removed under reduced pressure. The crude intermediate was purified by column chromatography in a solvent system of $2-$ $15 \% \mathrm{MeOH}$ in $\mathrm{CH}_{2} \mathrm{Cl}_{2}$ to yield 6-(3-cyclopropyl-1-tosyl- $1 \mathrm{H}$-pyrazol4-yl)quinazolin-4(3H)-one (31 mg; $0.0763 \mathrm{mmol} ; 87 \%)$ as a white solid. A mixture of 6-(3-cyclopropyl-1-tosyl-1H-pyrazol-4-yl)quinazolin-4(3H)-one $\left(5 \mathrm{mg} ; 0.0123 \mathrm{mmol} ; 1.0\right.$ equiv), $\left[\begin{array}{ll}1 \mathrm{M}\end{array}\right.$ $\mathrm{NaOH}_{(\text {aq }}(308 \mu \mathrm{L} ; 0.308$ mmol; 25 equiv), and EtOH ( $1 \mathrm{~mL} ; 0.012$ M) was heated at $50{ }^{\circ} \mathrm{C}$ for $2 \mathrm{~h}$ before being cooled to $\mathrm{RT}$ and neutralized with $\left[\begin{array}{ll}1 & \mathrm{M}\end{array}\right] \mathrm{HCl}_{(\mathrm{aq})}$. The mixture had solvent removed under reduced pressure, and the residue was purified by column chromatography in a solvent system of $2-10 \% \mathrm{MeOH}$ in $\mathrm{CH}_{2} \mathrm{Cl}_{2}$. 6 (3-Cyclopropyl- $1 \mathrm{H}$-pyrazol-4-yl)quinazolin-4(3H)-one $(2.1 \mathrm{mg}$; $0.00833 \mathrm{mmol}$; 68\%) was isolated as a white solid. ${ }^{1} \mathrm{H}$ NMR (500 $\mathrm{MHz}, \mathrm{MeOD}) \delta 8.49(\mathrm{q}, J=2.1 \mathrm{~Hz}, 1 \mathrm{H}), 8.12(\mathrm{~d}, J=8.6 \mathrm{~Hz}, 1 \mathrm{H})$, $8.10(\mathrm{~s}, 1 \mathrm{H}), 7.87(\mathrm{~s}, 1 \mathrm{H}), 7.75(\mathrm{~d}, J=8.4 \mathrm{~Hz}, 1 \mathrm{H}), 2.13-2.06(\mathrm{~m}$, $1 \mathrm{H}), 1.12-0.82(\mathrm{~m}, 4 \mathrm{H}) .{ }^{13} \mathrm{C}$ NMR $(126 \mathrm{MHz}, \mathrm{MeOD}) \delta 161.90$, $146.50,144.37,133.76,133.02,128.41,126.83,125.55,123.26$, 122.52, 118.86, 6.36, 6.35. HRMS (ESI) $m / z$ calc $\mathrm{C}_{14} \mathrm{H}_{13} \mathrm{~N}_{4} \mathrm{O}[\mathrm{M}+$ $\mathrm{H}]^{+}$253.1084; found $=253.1089$.

6-(3,5-Dimethyl-1H-pyrazol-4-yl)quinazolin-4(3H)-one, 6. Following general procedure 2, 6-bromoquinazolin-4(3H)-one (37 $\mathrm{mg} ; 0.165 \mathrm{mmol} ; 1$ equiv) was reacted with 3,5-dimethyl- $1 \mathrm{H}$ - 
pyrazole-4-boronic acid pinacol ester ( $43 \mathrm{mg} ; 0.194 \mathrm{mmol} ; 1.2$ equiv) in DME $(1.00 \mathrm{~mL} ; 0.16 \mathrm{M})$ were reacted to yield 6-(3,5-dimethyl- $1 \mathrm{H}$ pyrazol-4-yl)quinazolin-4(3H)-one (19 $\mathrm{mg} ; 0.0792 \mathrm{mmol} ; 50 \%)$ as a white solid. Reaction temperature: $150{ }^{\circ} \mathrm{C}$. Purification: $4-11 \%$ $\mathrm{MeOH}$ in $\mathrm{CH}_{2} \mathrm{Cl}_{2} .{ }^{1} \mathrm{H}$ NMR (500 MHz, DMSO) $\delta 12.17(\mathrm{~s}, 1 \mathrm{H}$ ), $8.11(\mathrm{~d}, J=8.4 \mathrm{~Hz}, 1 \mathrm{H}), 8.08(\mathrm{~d}, J=3.5 \mathrm{~Hz}, 1 \mathrm{H}), 7.77(\mathrm{~s}, 1 \mathrm{H}), 7.64$ $(\mathrm{d}, J=1.7 \mathrm{~Hz}, 1 \mathrm{H}), 7.59$ (dd, $J=8.2,1.8 \mathrm{~Hz}, 1 \mathrm{H}), 3.81(\mathrm{~s}, 3 \mathrm{H}), 2.45$ (s, 3H). ${ }^{13} \mathrm{C}$ NMR (126 MHz, DMSO) $\delta 160.95,149.73,146.12$, 140.30, 137.33, 136.47, 126.77, 126.12, 124.50, 120.49, 118.82, 36.90, 10.91. HRMS (ESI) $m / z$ calc $\mathrm{C}_{13} \mathrm{H}_{13} \mathrm{~N}_{4} \mathrm{O}[\mathrm{M}+\mathrm{H}]^{+} 241.1084$; found $=241.1081$.

6-(Quinolin-4-yl)quinazolin-4(3H)-one, 7. Following general procedure 2, quinolin-4-ylboronic acid (44 mg; $0.255 \mathrm{mmol} 1.0$ equiv), 6-bromoquinazolin-4(3H)-one ( $57 \mathrm{mg} ; 0.255 \mathrm{mmol} ; 1.0$ equiv), $\mathrm{PdCl}_{2}\left(\mathrm{PPh}_{3}\right)_{2}(9 \mathrm{mg} ; 0.0128 \mathrm{mmol} ; 0.05$ equiv), $[0.5 \mathrm{M}$ ] $\mathrm{Na}_{2} \mathrm{CO}_{3}(510 \mu \mathrm{L} ; 0.255 \mathrm{mmol} ; 1.0$ equiv) and 1,4-dioxane $(1.28 \mathrm{~mL}$; $0.20 \mathrm{M}$ ) were used to yield 6-(quinolin-4-yl)quinazolin-4(3H)-one (38 $\mathrm{mg} ; 0.139 \mathrm{mmol} ; 55 \%$ ) as a white solid. Reaction temperature: $120{ }^{\circ} \mathrm{C}$. Purification: $1-8 \% \mathrm{MeOH}$ in $\mathrm{CH}_{2} \mathrm{Cl}_{2} .{ }^{1} \mathrm{H} \mathrm{NMR}(500 \mathrm{MHz}$, $\mathrm{MeOH}) \delta 8.91(\mathrm{~d}, J=4.5 \mathrm{~Hz}, 1 \mathrm{H}), 8.43(\mathrm{~d}, J=1.9 \mathrm{~Hz}, 1 \mathrm{H}), 8.18-$ $8.12(\mathrm{~m}, 1 \mathrm{H}), 8.12(\mathrm{~s}, 1 \mathrm{H}), 7.97(\mathrm{dd}, J=8.4,2.1 \mathrm{~Hz}, 1 \mathrm{H}), 7.91(\mathrm{dd}, J$ $=8.4,1.3 \mathrm{~Hz}, 1 \mathrm{H}), 7.90(\mathrm{~d}, J=8.5 \mathrm{~Hz}, 1 \mathrm{H}), 7.83-7.79(\mathrm{~m}, 1 \mathrm{H})$, $7.62-7.57(\mathrm{~m}, 1 \mathrm{H}), 7.49(\mathrm{~d}, J=4.5 \mathrm{~Hz}, 1 \mathrm{H}) .{ }^{13} \mathrm{C}$ NMR $(126 \mathrm{MHz}$, $\left.\underline{\mathrm{MeOD}} / \mathrm{CDCl}_{3}\right) \delta 161.70,149.36,148.78,148.01,147.77,145.49$, $136.86,135.75,130.05,128.81,127.59,127.41,127.22,126.51$, $125.43,122.97,121.65$. HRMS (ESI) $m / z$ calc $\mathrm{C}_{17} \mathrm{H}_{12} \mathrm{~N}_{3} \mathrm{O}[\mathrm{M}+\mathrm{H}]^{+}$ 274.0975 ; found $=274.0985$.

6-(Quinolin-5-yl)quinazolin-4(3H)-one, 8. Following general procedure 2, quinolin-5-ylboronic acid (44 $\mathrm{mg} ; 0.255 \mathrm{mmol} 1.0$ equiv), 6-bromoquinazolin-4(3H)-one ( $57 \mathrm{mg}$; $0.255 \mathrm{mmol}$; 1.0 equiv), $\mathrm{PdCl}_{2}\left(\mathrm{PPh}_{3}\right)_{2}(9 \mathrm{mg} ; 0.0128 \mathrm{mmol} ; 0.05$ equiv), $[0.5 \mathrm{M}]$ $\mathrm{Na}_{2} \mathrm{CO}_{3}(510 \mu \mathrm{L} ; 0.255 \mathrm{mmol} ; 1.0$ equiv) and 1,4 -dioxane $(1.28 \mathrm{~mL}$; $0.20 \mathrm{M}$ ) were used to yield 6-(quinolin-5-yl)quinazolin-4(3H)-one (40 mg; $0.146 \mathrm{mmol} ; 57 \%$ ) as a white solid. Reaction temperature: $120{ }^{\circ} \mathrm{C}$. Purification: $1-8 \% \mathrm{MeOH}$ in $\mathrm{CH}_{2} \mathrm{Cl}_{2} .{ }^{1} \mathrm{H}$ NMR $(500 \mathrm{MHz}$, $\left.\underline{\mathrm{MeOD}} / \mathrm{CDCl}_{3}\right) \delta 8.88(\mathrm{dd}, J=4.2,1.6 \mathrm{~Hz}, 1 \mathrm{H}), 8.40-8.35(\mathrm{~m}, 1 \mathrm{H})$, $8.29(\mathrm{ddd}, J=8.6,1.7,0.9 \mathrm{~Hz}, 1 \mathrm{H}), 8.13(\mathrm{dt}, J=8.6,1.1 \mathrm{~Hz}, 1 \mathrm{H})$, $8.11(\mathrm{~s}, 1 \mathrm{H}), 7.93(\mathrm{dd}, J=8.4,2.1 \mathrm{~Hz}, 1 \mathrm{H}), 7.87(\mathrm{~d}, J=8.3 \mathrm{~Hz}, 1 \mathrm{H})$, $7.85(\mathrm{dd}, J=8.5,7.1 \mathrm{~Hz}, 1 \mathrm{H}), 7.63(\mathrm{dd}, J=7.1,1.2 \mathrm{~Hz}, 1 \mathrm{H}), 7.49$ $(\mathrm{dd}, J=8.6,4.2 \mathrm{~Hz}, 1 \mathrm{H}) .{ }^{13} \mathrm{C} \mathrm{NMR}\left(126 \mathrm{MHz}, \underline{\mathrm{MeOD}} / \mathrm{CDCl}_{3}\right) \delta$ $162.26,149.88,148.16,147.70,145.15,138.92,138.09,136.41$, $134.74,129.44,128.38,128.03,127.58,127.37,126.44,122.70$, 121.56. HRMS (ESI) $m / z$ calc $\mathrm{C}_{17} \mathrm{H}_{12} \mathrm{~N}_{3} \mathrm{O}[\mathrm{M}+\mathrm{H}]^{+} 274.0975$; found $=274.0984$.

6-(Pyrazolo[1,5-a]pyridin-3-yl)quinazolin-4(3H)-one, 9. (4Oxo-3,4-dihydroquinazolin-6-yl)boronic acid $(30 \mathrm{mg} ; 0.158 \mathrm{mmol}$; 1.0 equiv), 3-bromopyrazolo[1,5-a]pyridine ( $31 \mathrm{mg} ; 0.158 \mathrm{mmol} ; 1.0$ equiv), $\mathrm{K}_{2} \mathrm{CO}_{3}$ (66 mg; $4.74 \mathrm{mmol} ; 3.0$ equiv), bis(di-tert-butyl(4dimethylaminophenyl)phosphine)dichloropalladium(II) (5.6 mg; $0.00790 \mathrm{mmol} ; 5 \mathrm{~mol} \%)$, DME $(1 \mathrm{~mL} ; 0.079 \mathrm{M})$, and water $(1$ $\mathrm{mL} ; 0.079 \mathrm{M}$ ) were charged to a microwave vial. The vial was sealed and purged of air with five rounds of vacuum and $\mathrm{N}_{2}$. The mixture was stirred at $150{ }^{\circ} \mathrm{C}$ for $1 \mathrm{~h}$ under microwave irradiation. The reaction mixture was cooled to $<40{ }^{\circ} \mathrm{C}$ and diluted with $\mathrm{CH}_{2} \mathrm{Cl}_{2}$ (50 $\mathrm{mL}$ ) and passed through a syringe filter, and solvent was removed under a vacuum. The residue was purified initially by column chromatography using a solvent system of $0-8 \% \mathrm{MeOH}$ in $\mathrm{CH}_{2} \mathrm{Cl}_{2}$, followed by purification by preparative HPLC (see Supporting Information for details). 6-(Pyrazolo[1,5-a]pyridin-3-yl)quinazolin4(3H)-one (14 mg; $0.0537 \mathrm{mmol} ; 34 \%)$ was isolated as a white solid. ${ }^{1} \mathrm{H}$ NMR $(500 \mathrm{MHz}, \mathrm{MeOD}) \delta 8.53(\mathrm{dt}, J=7.0,1.1 \mathrm{~Hz}, 1 \mathrm{H}), 8.47$ $(\mathrm{d}, J=2.2 \mathrm{~Hz}, 1 \mathrm{H}), 8.25(\mathrm{~s}, 1 \mathrm{H}), 8.07(\mathrm{dd}, J=8.4,2.2 \mathrm{~Hz}, 1 \mathrm{H}), 8.01$ (s, $1 \mathrm{H}), 7.99(\mathrm{dt}, J=9.1,1.2 \mathrm{~Hz}, 1 \mathrm{H}), 7.79(\mathrm{~d}, J=8.5 \mathrm{~Hz}, 1 \mathrm{H}), 7.34$ (ddd, $J=9.0,6.7,1.1 \mathrm{~Hz}, 1 \mathrm{H}), 6.94(\mathrm{td}, J=6.9,1.3 \mathrm{~Hz}, 1 \mathrm{H}) .{ }^{13} \mathrm{C}$ NMR (126 MHz, MeOD) $\delta 161.94,146.63,144.09,140.21,137.18$, $133.48,132.45,128.82,127.64,125.37,123.09,123.04,117.31$, 113.02, 111.42. HRMS (ESI) $m / z$ calc $\mathrm{C}_{15} \mathrm{H}_{11} \mathrm{~N}_{4} \mathrm{O}[\mathrm{M}+\mathrm{H}]^{+}$ 263.0927; found $=263.0929$.

5-Methyl-6-(quinolin-4-yl)quinazolin-4(3H)-one, 10. Following general procedure 2, quinolin-4-ylboronic acid (22 mg; 0.126 mmol; 1.0 equiv), $\mathrm{PdCl}_{2}\left(\mathrm{PPh}_{3}\right)_{2}$ (4.4 mg; $0.0063 \mathrm{mmol} ; 0.05$ equiv), 6-bromo-5-methylquinazolin-4(3H)-one $(30 \mathrm{mg} ; 0.126 \mathrm{mmol} ; 1.0$ equiv), $[0.5 \mathrm{M}] \mathrm{Na}_{2} \mathrm{CO}_{3(\mathrm{aq})}(252 \mu \mathrm{L} ; 0.126 \mathrm{mmol} ; 1.0$ equiv) and $1,4-$ dioxane $(2 \mathrm{~mL} ; 0.063 \mathrm{M})$ were used to yield 5-methyl-6-(quinolin-4yl)quinazolin-4(3H)-one (18 mg; $0.0627 \mathrm{mmol} ; 50 \%)$ as a white solid. Reaction temperature: $120{ }^{\circ} \mathrm{C}$. Purification: $3-20 \% \mathrm{MeOH}$ in $\mathrm{CH}_{2} \mathrm{Cl}_{2} \cdot{ }^{1} \mathrm{H}$ NMR $\left(500 \mathrm{MHz}, \mathrm{CDCl}_{3}\right) \delta 8.87(\mathrm{~d}, J=4.4 \mathrm{~Hz}, 1 \mathrm{H})$, $8.13-8.10(\mathrm{~m}, 1 \mathrm{H}), 7.96(\mathrm{~d}, J=3.7 \mathrm{~Hz}, 1 \mathrm{H}), 7.70(\mathrm{ddd}, J=8.4,6.8$, $1.6 \mathrm{~Hz}, 1 \mathrm{H}), 7.62(\mathrm{~d}, J=8.2 \mathrm{~Hz}, 1 \mathrm{H}), 7.53-7.51(\mathrm{~m}, 1 \mathrm{H}), 7.43(\mathrm{ddd}$, $J=8.1,6.7,1.2 \mathrm{~Hz}, 1 \mathrm{H}), 7.37(\mathrm{dd}, J=8.4,1.5 \mathrm{~Hz}, 1 \mathrm{H}), 7.30-7.25$ $(\mathrm{m}, 1 \mathrm{H}), 2.49(\mathrm{~s}, 3 \mathrm{H}) .{ }^{13} \mathrm{C} \mathrm{NMR}\left(126 \mathrm{MHz}, \mathrm{CDCl}_{3}\right) \delta 162.63$, $150.23,149.54,148.41,147.68,144.71,139.31,136.93,135.28$, 129.98, 129.03, 127.89, 127.22, 125.67, 125.05, 121.85, 121.58, 19.67. HRMS (ESI) $m / z$ calc $\mathrm{C}_{18} \mathrm{H}_{14} \mathrm{~N}_{3} \mathrm{O}[\mathrm{M}+\mathrm{H}]^{+}$288.1132; found $=$ 288.1144 .

5-Methyl-6-(quinolin-5-yl)quinazolin-4(3H)-one, 11. Following general procedure 2, quinolin-5-ylboronic acid (22 $\mathrm{mg} ; 0.126$ mmol; 1.0 equiv), $\mathrm{PdCl}_{2}\left(\mathrm{PPh}_{3}\right)_{2}$ ( $4.4 \mathrm{mg} ; 0.0063 \mathrm{mmol} ; 0.05$ equiv), 6-bromo-5-methylquinazolin- $4(3 \mathrm{H})$-one $(30 \mathrm{mg} ; 0.126 \mathrm{mmol} ; 1.0$ equiv), $[0.5 \mathrm{M}] \mathrm{Na}_{2} \mathrm{CO}_{3(\mathrm{aq})}(252 \mu \mathrm{L} ; 0.126 \mathrm{mmol} ; 1.0$ equiv) and $1,4-$ dioxane $(2 \mathrm{~mL} ; 0.063 \mathrm{M}$ ) were used to yield 5-methyl-6-(quinolin-5yl)quinazolin-4(3H)-one $(21 \mathrm{mg} ; 0.0731 \mathrm{mmol} ; 58 \%)$ was isolated as a white solid. Reaction temperature: $120{ }^{\circ} \mathrm{C}$. Purification: $3-20 \%$ $\mathrm{MeOH}$ in $\mathrm{CH}_{2} \mathrm{Cl}_{2} .{ }^{1} \mathrm{H}$ NMR ( $\left.500 \mathrm{MHz}, \mathrm{CDCl}_{3}\right) \delta 8.86(\mathrm{dd}, J=4.2$, $1.7 \mathrm{~Hz}, 1 \mathrm{H}), 8.13(\mathrm{dt}, J=8.6,1.1 \mathrm{~Hz}, 1 \mathrm{H}), 7.97(\mathrm{~s}, 1 \mathrm{H}), 7.79(\mathrm{dd}, J=$ 8.6, $7.0 \mathrm{~Hz}, 1 \mathrm{H}), 7.76-7.72(\mathrm{~m}, 1 \mathrm{H}), 7.64(\mathrm{~d}, J=8.3 \mathrm{~Hz}, 1 \mathrm{H}), 7.58$ $(\mathrm{d}, J=8.3 \mathrm{~Hz}, 1 \mathrm{H}), 7.42(\mathrm{dd}, J=7.0,1.2 \mathrm{~Hz}, 1 \mathrm{H}), 7.33(\mathrm{dd}, J=8.5$, $4.2 \mathrm{~Hz}, 1 \mathrm{H}), 2.50(\mathrm{~s}, 3 \mathrm{H}) .{ }^{13} \mathrm{C} \mathrm{NMR}\left(126 \mathrm{MHz}, \mathrm{CDCl}_{3}\right) \delta 162.37$, 150.09 , 147.72, 144.30, 139.89, 139.20, 138.41, 137.77, 136.31, 134.56, 129.33, 128.66, 127.78, 127.18, 125.01, 121.43, 120.96, 19.70. HRMS (ESI) $m / z$ calc $\mathrm{C}_{18} \mathrm{H}_{14} \mathrm{~N}_{3} \mathrm{O}[\mathrm{M}+\mathrm{H}]^{+}$288.1132; found = 288.1138.

3-Methyl-6-(quinolin-4-yl)quinazolin-4(3H)-one, 12. Following general procedure 2, quinolin-4-ylboronic acid $(25 \mathrm{mg} ; 0.144$ mmol; 1.0 equiv), $\mathrm{PdCl}_{2}\left(\mathrm{PPh}_{3}\right)_{2}$ (5.1 mg; $0.00721 \mathrm{mmol} ; 0.05$ equiv), 6-bromo-3-methylquinazolin-4(3H)-one $(34 \mathrm{mg} ; 0.144 \mathrm{mmol} ; 1.0$ equiv), $[0.5 \mathrm{M}] \mathrm{Na}_{2} \mathrm{CO}_{3(\mathrm{aq})}(288 \mu \mathrm{L} ; 0.144 \mathrm{mmol} ; 1.0$ equiv), and 1,4-dioxane $(2 \mathrm{~mL} ; 0.072 \mathrm{M})$ were used to yield 3-methyl-6(quinolin-4-yl)quinazolin-4(3H)-one $(27 \mathrm{mg} ; 0.0940 \mathrm{mmol} ; 65 \%)$ as a white solid. Reaction temperature: $130{ }^{\circ} \mathrm{C}$. Purification: $0-8 \%$ $\mathrm{MeOH}$ in $\mathrm{CH}_{2} \mathrm{Cl}_{2} .{ }^{1} \mathrm{H}$ NMR (500 MHz, $\left.\mathrm{CDCl}_{3} / \mathrm{MeOD}\right) \delta 8.77$ (d, $J$ $=4.6 \mathrm{~Hz}, 1 \mathrm{H}), 8.31(\mathrm{~d}, J=2.0 \mathrm{~Hz}, 1 \mathrm{H}), 8.09(\mathrm{~s}, 1 \mathrm{H}), 8.04-7.99(\mathrm{~m}$, $1 \mathrm{H}), 7.79(\mathrm{dd}, J=8.3,2.0 \mathrm{~Hz}, 1 \mathrm{H}), 7.74(\mathrm{~d}, J=8.5 \mathrm{~Hz}, 2 \mathrm{H}), 7.64(\mathrm{t}, J$ $=7.6 \mathrm{~Hz}, 2 \mathrm{H}), 7.46-7.39(\mathrm{~m}, 1 \mathrm{H}), 7.31(\mathrm{~d}, J=4.6 \mathrm{~Hz}, 1 \mathrm{H}), 3.52(\mathrm{~s}$, $3 \mathrm{H}) .{ }^{13} \mathrm{C}$ NMR $\left(126 \mathrm{MHz}, \mathrm{CDCl}_{3}\right) \delta 161.50,149.40,149.35,147.93$, $147.87,147.51,136.90,135.46,129.96,128.89,127.45,127.33$, $127.27,126.40,125.33,121.84,121.57,34.11$. HRMS (ESI) $\mathrm{m} / z$ calc $\mathrm{C}_{18} \mathrm{H}_{14} \mathrm{~N}_{3} \mathrm{O}[\mathrm{M}+\mathrm{H}]^{+} 288.1132$; found $=288.1124$.

3-Methyl-6-(quinolin-5-yl)quinazolin-4(3H)-one, 13. Following general procedure 2, quinolin-5-ylboronic acid (25 mg; 0.144 mmol; 1.0 equiv), $\mathrm{PdCl}_{2}\left(\mathrm{PPh}_{3}\right)_{2}(5.1 \mathrm{mg} ; 0.00721 \mathrm{mmol} ; 0.05$ equiv), 6-bromo-3-methylquinazolin-4(3H)-one $(34 \mathrm{mg} ; 0.144 \mathrm{mmol} ; 1.0$ equiv), $\left[0.5 \mathrm{M}\right.$ ] $\mathrm{Na}_{2} \mathrm{CO}_{3(\mathrm{aq})}(288 \mu \mathrm{L} ; 0.144 \mathrm{mmol} ; 1.0$ equiv), and 1,4-dioxane $(2 \mathrm{~mL} ; 0.072 \mathrm{M})$ were used to yield 3-methyl-6(quinolin-5-yl)quinazolin-4(3H)-one (23 mg; $0.0801 \mathrm{mmol}$; 56\%) as a white solid. Reaction temperature: $130{ }^{\circ} \mathrm{C}$. Purification: $0-8 \%$ $\mathrm{MeOH}$ in $\mathrm{CH}_{2} \mathrm{Cl}_{2} .{ }^{1} \mathrm{H}$ NMR (500 MHz, $\left.\mathrm{CDCl}_{3} / \mathrm{MeOD}\right) \delta 8.78$ (dd, $J=4.2,1.7 \mathrm{~Hz}, 1 \mathrm{H}), 8.30(\mathrm{~d}, J=1.8 \mathrm{~Hz}, 1 \mathrm{H}), 8.14$ (ddd, $J=8.6,1.8$, $1.0 \mathrm{~Hz}, 1 \mathrm{H}), 8.10(\mathrm{~d}, J=1.4 \mathrm{~Hz}, 1 \mathrm{H}), 8.04(\mathrm{dt}, J=8.5,1.1 \mathrm{~Hz}, 1 \mathrm{H})$, $7.78(\mathrm{dd}, J=8.3,2.0 \mathrm{~Hz}, 1 \mathrm{H}), 7.75(\mathrm{~d}, J=8.4 \mathrm{~Hz}, 1 \mathrm{H}), 7.72(\mathrm{dd}, J=$ 8.6, $7.1 \mathrm{~Hz}, 1 \mathrm{H}), 7.49$ (dd, $J=7.1,1.3 \mathrm{~Hz}, 1 \mathrm{H}), 7.34$ (ddd, $J=8.7$, 4.3, $1.3 \mathrm{~Hz}, 1 \mathrm{H}), 3.56(\mathrm{~d}, J=1.4 \mathrm{~Hz}, 3 \mathrm{H}) .{ }^{13} \mathrm{C}$ NMR $(126 \mathrm{MHz}$, $\left.\mathrm{CDCl}_{3} / \mathrm{MeOD}\right) \delta 161.58,149.90,147.74,147.49,147.29,138.73$, $138.44,136.10,134.47,129.30,128.63,127.92,127.44,127.29$, $126.47,121.74,121.45$, 34.11. HRMS (ESI) $m / z$ calc $\mathrm{C}_{18} \mathrm{H}_{14} \mathrm{~N}_{3} \mathrm{O}[\mathrm{M}$ $+\mathrm{H}]^{+}$288.1132; found $=288.113$.

2-Methyl-6-(quinolin-4-yl)quinazolin-4(3H)-one, 14. Following general procedure 2, quinolin-4-ylboronic acid $(25 \mathrm{mg} ; 0.144$ mmol; 1.0 equiv), $\mathrm{PdCl}_{2}\left(\mathrm{PPh}_{3}\right)_{2}(5.1 \mathrm{mg} ; 0.00721 \mathrm{mmol} ; 0.05$ equiv), 6-bromo-2-methylquinazolin-4(3H)-one $(34 \mathrm{mg} ; 0.144 \mathrm{mmol} ; 1.0$ 
equiv), $[0.5 \mathrm{M}] \mathrm{Na}_{2} \mathrm{CO}_{3(\mathrm{aq})}(288 \mu \mathrm{L} ; 0.144 \mathrm{mmol} ; 1.0$ equiv), and 1,4-dioxane $(2 \mathrm{~mL} ; 0.072 \mathrm{M})$ were used to yield 2-methyl-6(quinolin-4-yl)quinazolin-4(3H)-one $(29 \mathrm{mg} ; 0.101 \mathrm{mmol} ; 70 \%)$ as a white solid. Reaction temperature: $130{ }^{\circ} \mathrm{C}$. Purification: $0-8 \%$ $\mathrm{MeOH}$ in $\mathrm{CH}_{2} \mathrm{Cl}_{2} .{ }^{1} \mathrm{H}$ NMR ( $\left.500 \mathrm{MHz}, \mathrm{MeOD}\right) \delta 8.90$ (d, $J=4.5$ $\mathrm{Hz}, 1 \mathrm{H}), 8.36(\mathrm{~d}, J=2.1 \mathrm{~Hz}, 1 \mathrm{H}), 8.14(\mathrm{dt}, J=8.5,1.0 \mathrm{~Hz}, 1 \mathrm{H}), 7.95$ (dd, $J=8.4,2.2 \mathrm{~Hz}, 1 \mathrm{H}), 7.93-7.91(\mathrm{~m}, 1 \mathrm{H}), 7.83-7.78(\mathrm{~m}, 2 \mathrm{H})$, $7.59(\mathrm{ddd}, J=8.3,6.9,1.2 \mathrm{~Hz}, 1 \mathrm{H}), 7.51(\mathrm{~d}, J=4.5 \mathrm{~Hz}, 1 \mathrm{H}), 2.53(\mathrm{~s}$, $3 \mathrm{H}) .{ }^{13} \mathrm{C}$ NMR (126 MHz, MeOD) $\delta 162.60,155.65,149.36,148.31$, $147.93,147.88,135.76,135.69,129.94,128.56,127.29,126.97$, $126.52,126.38,125.41,121.59,120.73,20.69$. HRMS (ESI) $\mathrm{m} / z$ calc $\mathrm{C}_{18} \mathrm{H}_{14} \mathrm{~N}_{3} \mathrm{O}[\mathrm{M}+\mathrm{H}]^{+}$288.1132; found $=288.1133$.

2-Methyl-6-(quinolin-5-yl)quinazolin-4(3H)-one, 15. Following general procedure 2, quinolin-5-ylboronic acid $(25 \mathrm{mg}$; 0.144 mmol; 1.0 equiv), $\mathrm{PdCl}_{2}\left(\mathrm{PPh}_{3}\right)_{2}(5.1 \mathrm{mg} ; 0.00721 \mathrm{mmol} ; 0.05$ equiv), 6-bromo-2-methylquinazolin-4(3H)-one $(34 \mathrm{mg} ; 0.144 \mathrm{mmol}$; 1.0 equiv), $[0.5 \mathrm{M}] \mathrm{Na}_{2} \mathrm{CO}_{3(\mathrm{aq})}(288 \mu \mathrm{L} ; 0.144 \mathrm{mmol} ; 1.0$ equiv), and 1,4-dioxane (2 mL; $0.072 \mathrm{M})$ were used to yield 2-methyl-6(quinolin-5-yl)quinazolin-4(3H)-one $(24 \mathrm{mg} ; 0.0836 \mathrm{mmol} ; 58 \%$ ) as a white solid. Reaction temperature: $130{ }^{\circ} \mathrm{C}$. Purification: $0-8 \%$ $\mathrm{MeOH}$ in $\mathrm{CH}_{2} \mathrm{Cl}_{2} .{ }^{1} \mathrm{H}$ NMR $(500 \mathrm{MHz}, \mathrm{MeOD}) \delta 8.86$ (dd, $J=4.3$, $1.7 \mathrm{~Hz}, 1 \mathrm{H}$ ), 8.30 (d, $J=2.0 \mathrm{~Hz}, 1 \mathrm{H}), 8.27$ (ddd, $J=8.6,1.7,0.9 \mathrm{~Hz}$, $1 \mathrm{H}), 8.11(\mathrm{dt}, J=8.5,1.1 \mathrm{~Hz}, 1 \mathrm{H}), 7.86(\mathrm{dd}, J=8.4,2.1 \mathrm{~Hz}, 1 \mathrm{H})$, $7.82(\mathrm{dd}, J=8.5,7.1 \mathrm{~Hz}, 1 \mathrm{H}), 7.76(\mathrm{~d}, J=8.4 \mathrm{~Hz}, 1 \mathrm{H}), 7.60(\mathrm{dd}, J=$ $7.1,1.2 \mathrm{~Hz}, 1 \mathrm{H}), 7.46(\mathrm{dd}, J=8.6,4.3 \mathrm{~Hz}, 1 \mathrm{H}), 2.51(\mathrm{~s}, 3 \mathrm{H}) .{ }^{13} \mathrm{C}$ NMR (126 MHz, MeOD) $\delta 162.79,154.99,149.84,148.15,147.72$, $139.04,137.35,136.41,134.78,129.43,128.28,127.96,127.22$, $126.62,126.43,121.49,120.65,20.96$. HRMS (ESI) $\mathrm{m} / z$ calc $\mathrm{C}_{18} \mathrm{H}_{14} \mathrm{~N}_{3} \mathrm{O}[\mathrm{M}+\mathrm{H}]^{+}$288.1132; found $=288.1144$.

3-(4-Morpholinophenyl)-6-(quinolin-4-yl)quinazolin-4(3H)one, 16. Following general procedure 2, 6-bromo-3-(4morpholinophenyl)quinazolin-4(3H)-one $(333 \mathrm{mg} ; 0.867 \mathrm{mmol} ; 1.0$ equiv), quinolin-4-yl boronic acid (170 mg; $0.867 \mathrm{mmol} ; 1.0$ equiv), $\mathrm{PdCl}_{2}\left(\mathrm{PPh}_{3}\right)_{2} \quad(30 \mathrm{mg} ; 0.0433 \mathrm{mmol} ; 0.05$ equiv $),[0.5 \mathrm{M}]$ $\mathrm{Na}_{2} \mathrm{CO}_{3(\mathrm{aq})}(1.73 \mathrm{~mL} ; 0.867 \mathrm{mmol} ; 1.0$ equiv) and 1,4-dioxane (10 $\mathrm{mL} ; 0.087 \mathrm{M})$ were used to yield 3-(4-morpholinophenyl)-6(quinolin-4-yl)quinazolin-4(3H)-one (180 mg; $0.414 \mathrm{mmol} ; 48 \%$ ) as pale purple solid. Reaction temperature: $150{ }^{\circ} \mathrm{C}$. Purification: $0-$ $8 \% \mathrm{MeOH}$ in $\mathrm{CH}_{2} \mathrm{Cl}_{2} .{ }^{1} \mathrm{H}$ NMR $\left(500 \mathrm{MHz}, \mathrm{CDCl}_{3}\right) \delta 9.00(\mathrm{~d}, J=4.4$ $\mathrm{Hz}, 1 \mathrm{H}), 8.54(\mathrm{dd}, J=1.8,0.9 \mathrm{~Hz}, 1 \mathrm{H}), 8.25-8.20(\mathrm{~m}, 2 \mathrm{H}), 7.95-$ $7.94(\mathrm{~m}, 2 \mathrm{H}), 7.92-7.89(\mathrm{~m}, 1 \mathrm{H}), 7.78(\mathrm{ddd}, J=8.3,6.8,1.4 \mathrm{~Hz}$, $1 \mathrm{H}), 7.55$ (ddd, $J=8.3,6.8,1.3 \mathrm{~Hz}, 1 \mathrm{H}), 7.43(\mathrm{~d}, J=4.4 \mathrm{~Hz}, 1 \mathrm{H})$, 7.37-7.34 (m, 2H), 7.08-7.02 (m, 2H), 3.92-3.88 (m, 4H), 3.29$3.23(\mathrm{~m}, 4 \mathrm{H}) .{ }^{13} \mathrm{C}$ NMR $\left(126 \mathrm{MHz} \mathrm{CDCl}_{3}\right) \delta 160.95,151.67$, $149.96,148.70,147.91,147.22,146.86,137.35,136.15,135.63$, $130.04,129.59,128.03,127.95,127.67,127.10,125.37,122.62$, $121.57,115.91,115.87,66.73,48.74$. HRMS (ESI) $\mathrm{m} / z$ calc $\mathrm{C}_{27} \mathrm{H}_{23} \mathrm{~N}_{4} \mathrm{O}_{2}[\mathrm{M}+\mathrm{H}]^{+}$435.1816; found = 435.1814.

3-Phenyl-6-(quinolin-4-yl)quinazolin-4(3H)-one, 17. Following general procedure 2, quinolin-4-ylboronic acid (25 mg; 0.144 mmol; 1.0 equiv), $\mathrm{PdCl}_{2}\left(\mathrm{PPh}_{3}\right)_{2}$ (5.1 mg; $0.00721 \mathrm{mmol} ; 0.05$ equiv), 6-bromo-3-phenylquinazolin-4(3H)-one $(42 \mathrm{mg} ; 0.144 \mathrm{mmol}$; 1.0 equiv), $[0.5 \mathrm{M}] \mathrm{Na}_{2} \mathrm{CO}_{3(\mathrm{aq})}(288 \mu \mathrm{L} ; 0.144 \mathrm{mmol} ; 1.0$ equiv), and 1,4-dioxane $(2 \mathrm{~mL} ; 0.072 \mathrm{M})$ were used to yield 3-phenyl-6(quinolin-4-yl)quinazolin-4(3H)-one $(37 \mathrm{mg} ; 0.106 \mathrm{mmol} ; 74 \%)$ as a white solid. Reaction temperature: $130{ }^{\circ} \mathrm{C}$. Purification: $0-8 \%$ $\mathrm{MeOH}$ in $\mathrm{CH}_{2} \mathrm{Cl}_{2} .{ }^{1} \mathrm{H}$ NMR $\left(500 \mathrm{MHz}, \mathrm{CDCl}_{3}\right) \delta 8.98(\mathrm{~d}, J=4.4$ $\mathrm{Hz}, 1 \mathrm{H}), 8.54(\mathrm{dd}, J=1.8,0.9 \mathrm{~Hz}, 1 \mathrm{H}), 8.23(\mathrm{~s}, 1 \mathrm{H}), 8.21(\mathrm{dt}, J=8.6$, $0.8 \mathrm{~Hz}, 1 \mathrm{H}), 7.96-7.95(\mathrm{~m}, 2 \mathrm{H}), 7.90(\mathrm{dd}, J=8.5,1.4 \mathrm{~Hz}, 1 \mathrm{H}), 7.77$ (ddd, $J=8.4,6.9,1.5 \mathrm{~Hz}, 1 \mathrm{H}), 7.63-7.50(\mathrm{~m}, 4 \mathrm{H}), 7.48-7.45(\mathrm{~m}$, $2 \mathrm{H}), 7.43(\mathrm{~d}, J=4.4 \mathrm{~Hz}, 1 \mathrm{H}) .{ }^{13} \mathrm{C} \operatorname{NMR}\left(126 \mathrm{MHz}, \mathrm{CDCl}_{3}\right) \delta$ $160.63,149.82,149.73,148.50,147.80,146.83,137.47,137.24$, $135.81,129.77,129.77,129.74,129.37,128.04,127.97,127.21$, $126.96,126.42,125.34,122.57,121.59$. HRMS (ESI) $\mathrm{m} / z$ calc $\mathrm{C}_{23} \mathrm{H}_{16} \mathrm{~N}_{3} \mathrm{O}[\mathrm{M}+\mathrm{H}]^{+}$350.1288; found $=350.1303$.

3-Cyclohexyl-6-(quinolin-4-yl)quinazolin-4(3H)-one, 18. Following general procedure 2, quinolin-4-ylboronic acid (25 mg; 0.144 mmol; 1.0 equiv), $\mathrm{PdCl}_{2}\left(\mathrm{PPh}_{3}\right)_{2}$ (5.1 mg; $0.00721 \mathrm{mmol} ; 0.05$ equiv), 6-bromo-3-cyclohexylquinazolin-4(3H)-one ( $44 \mathrm{mg} ; 0.144 \mathrm{mmol} ; 1.0$ equiv), [0.5 M] $\mathrm{Na}_{2} \mathrm{CO}_{3(\mathrm{aq})}(288 \mu \mathrm{L} ; 0.144 \mathrm{mmol} ; 1.0$ equiv) and $1,4-$ dioxane ( $2 \mathrm{~mL} ; 0.072 \mathrm{M}$ ) were used to yield 3-cyclohexyl-6-(quinolin4 -yl)quinazolin-4(3H)-one (42 $\mathrm{mg} ; 0.118 \mathrm{mmol} ; 82 \%$ ) as a pale yellow glass. Reaction temperature: $130{ }^{\circ} \mathrm{C}$. Purification: $0-8 \%$ $\mathrm{MeOH}$ in $\mathrm{CH}_{2} \mathrm{Cl}_{2} .{ }^{1} \mathrm{H}$ NMR ( $\left.500 \mathrm{MHz}, \mathrm{CDCl}_{3}\right) \delta 8.97$ (d, $J=4.4$ $\mathrm{Hz}, 1 \mathrm{H}), 8.48$ (dd, $J=2.0,0.6 \mathrm{~Hz}, 1 \mathrm{H}), 8.22(\mathrm{~s}, 1 \mathrm{H}), 7.90(\mathrm{dd}, J=$ $8.3,2.0 \mathrm{~Hz}, 1 \mathrm{H}), 7.87(\mathrm{~d}, J=8.1 \mathrm{~Hz}, 1 \mathrm{H}), 7.77(\mathrm{ddd}, J=8.4,6.8,1.4$ $\mathrm{Hz}, 1 \mathrm{H}$ ), 7.66 (ddd, $J=12.0,8.3,1.4 \mathrm{~Hz}, 1 \mathrm{H}$ ), 7.54 (ddd, $J=8.2,6.8$, $1.3 \mathrm{~Hz}, 1 \mathrm{H}), 7.47(\mathrm{td}, J=7.6,3.0 \mathrm{~Hz}, 1 \mathrm{H}), 7.41(\mathrm{~d}, J=4.4 \mathrm{~Hz}, 1 \mathrm{H})$, $4.85(\mathrm{tt}, J=12.3,3.7 \mathrm{~Hz}, 1 \mathrm{H}), 2.09-2.02(\mathrm{~m}, 2 \mathrm{H}), 1.97(\mathrm{dt}, J=13.8$, $3.6 \mathrm{~Hz}, 2 \mathrm{H}), 1.82(\mathrm{~d}, J=13.5 \mathrm{~Hz}, 1 \mathrm{H}), 1.69(\mathrm{qd}, J=12.4,3.4 \mathrm{~Hz}$, $2 \mathrm{H}), 1.55(\mathrm{qt}, J=13.1,3.4 \mathrm{~Hz}, 2 \mathrm{H}), 1.34-1.24(\mathrm{~m}, 1 \mathrm{H}) .{ }^{13} \mathrm{C} \mathrm{NMR}$ $\left(126 \mathrm{MHz}, \mathrm{CDCl}_{3}\right) \delta 160.55,149.83,149.75,148.51,147.41,144.68$ $136.87,135.35,132.02,129.76,128.59,127.87,127.60,127.13$, $126.47,122.08,121.58,53.67,32.63,25.88,25.24$. HRMS (ESI) $\mathrm{m} / z$ calc $\mathrm{C}_{23} \mathrm{H}_{22} \mathrm{~N}_{3} \mathrm{O}[\mathrm{M}+\mathrm{H}]^{+} 356.1758$; found $=356.1768$.

3-(3-Morpholinopropyl)-6-(quinolin-4-yl)quinazolin-4(3H)one, 19. Following general procedure 2, quinolin-4-ylboronic acid (25 mg; $0.144 \mathrm{mmol} ; 1.0$ equiv), $\mathrm{PdCl}_{2}\left(\mathrm{PPh}_{3}\right)_{2}$ (5.1 mg; 0.00721 mmol; 0.05 equiv), 6-bromo-3-(3-morpholinopropyl)quinazolin$4(3 \mathrm{H})$-one (51 mg; $0.144 \mathrm{mmol} ; 1.0$ equiv), $[0.5 \mathrm{M}] \mathrm{Na}_{2} \mathrm{CO}_{3(\mathrm{aq})}$ $(288 \mu \mathrm{L} ; 0.144 \mathrm{mmol} ; 1.0$ equiv) and 1,4-dioxane $(2 \mathrm{~mL} ; 0.072 \mathrm{M})$ were used to yield 3-(3-morpholinopropyl)-6-(quinolin-4-yl)quinazolin-4(3H)-one $(21 \mathrm{mg} ; 0.0525 \mathrm{mmol} ; 36 \%)$ as a pale yellow glass. Reaction temperature: $130{ }^{\circ} \mathrm{C}$. Purification: $0-8 \% \mathrm{MeOH}$ in $\mathrm{CH}_{2} \mathrm{Cl}_{2} \cdot{ }^{1} \mathrm{H}$ NMR $\left(500 \mathrm{MHz}, \mathrm{CDCl}_{3}\right) \delta 8.93(\mathrm{~d}, J=4.4 \mathrm{~Hz}, 1 \mathrm{H})$, $8.44(\mathrm{~d}, J=2.0 \mathrm{~Hz}, 1 \mathrm{H}), 8.22(\mathrm{~s}, 1 \mathrm{H}), 8.18(\mathrm{dd}, J=8.6,1.2 \mathrm{~Hz}, 1 \mathrm{H})$, $7.90(\mathrm{dd}, J=8.4,2.0 \mathrm{~Hz}, 1 \mathrm{H}), 7.88-7.84(\mathrm{~m}, 2 \mathrm{H}), 7.76$ (ddd, $J=8.4$, $6.8,1.4 \mathrm{~Hz}, 1 \mathrm{H}), 7.53(\mathrm{ddd}, J=8.4,6.9,1.3 \mathrm{~Hz}, 1 \mathrm{H}), 7.40(\mathrm{~d}, J=4.4$ $\mathrm{Hz}, 1 \mathrm{H}), 4.12(\mathrm{t}, J=6.7 \mathrm{~Hz}, 2 \mathrm{H}), 3.68(\mathrm{t}, J=4.6 \mathrm{~Hz}, 4 \mathrm{H}), 2.42(\mathrm{q}, J=$ $6.4 \mathrm{~Hz}, 6 \mathrm{H}), 2.02(\mathrm{p}, J=6.7 \mathrm{~Hz}, 2 \mathrm{H}) .{ }^{13} \mathrm{C}$ NMR $\left(126 \mathrm{MHz}, \mathrm{CDCl}_{3}\right)$ $\delta 161.04,149.65,148.28,147.93,147.90,147.25,136.97,135.48$, $129.82,129.48,127.65,127.46,127.24,126.43,125.36,122.21$, $121.59,66.85,54.91,53.34,45.39,24.85$. HRMS (ESI) $\mathrm{m} / z$ calc $\mathrm{C}_{24} \mathrm{H}_{25} \mathrm{~N}_{4} \mathrm{O}_{2}[\mathrm{M}+\mathrm{H}]^{+}$401.1972; found $=401.1984$.

3-(4-(Dimethylamino)phenyl)-6-(quinolin-4-yl)quinazolin4(3H)-one, 20. Following general procedure 2, quinolin-4-ylboronic acid (25 mg; $0.144 \mathrm{mmol} ; 1.0$ equiv), $\mathrm{PdCl}_{2}\left(\mathrm{PPh}_{3}\right)_{2}(5.1 \mathrm{mg} ; 0.00721$ mmol; 0.05 equiv), 6-bromo-3-(4-(dimethylamino)phenyl)quinazolin-4(3H)-one (49 mg; $0.144 \mathrm{mmol} ; 1.0$ equiv), $[0.5 \mathrm{M}]$ $\mathrm{Na}_{2} \mathrm{CO}_{3(\mathrm{aq})}(288 \mu \mathrm{L} ; 0.144 \mathrm{mmol} ; 1.0$ equiv), and 1,4-dioxane $(2 \mathrm{~mL}$; $0.072 \mathrm{M})$ were used to yield 3-(4-(dimethylamino)phenyl)-6(quinolin-4-yl)quinazolin-4(3H)-one ( $45 \mathrm{mg} ; 0.115 \mathrm{mmol} ; 80 \%$ ) as a white solid. Reaction temperature: $130{ }^{\circ} \mathrm{C}$. Purification: $0-8 \%$ $\mathrm{MeOH}$ in $\mathrm{CH}_{2} \mathrm{Cl}_{2} .{ }^{1} \mathrm{H}$ NMR $\left(500 \mathrm{MHz}, \mathrm{CDCl}_{3}\right) \delta 9.00$ (d, $J=4.4$ $\mathrm{Hz}, 1 \mathrm{H}), 8.54$ (dd, $J=1.6,1.0 \mathrm{~Hz}, 1 \mathrm{H}), 8.23-8.20(\mathrm{~m}, 2 \mathrm{H}), 7.93-$ $7.92(\mathrm{~m}, 2 \mathrm{H}), 7.91(\mathrm{ddd}, J=8.5,1.4,0.6 \mathrm{~Hz}, 1 \mathrm{H}), 7.76(\mathrm{ddd}, J=8.4$, $6.8,1.4 \mathrm{~Hz}, 1 \mathrm{H}), 7.54$ (ddd, $J=8.3,6.9,1.3 \mathrm{~Hz}, 1 \mathrm{H}), 7.42(\mathrm{~d}, J=4.4$ $\mathrm{Hz}, 1 \mathrm{H}), 7.29(\mathrm{dd}, J=8.8,2.0 \mathrm{~Hz}, 2 \mathrm{H}), 6.85-6.80(\mathrm{~m}, 2 \mathrm{H}), 3.03(\mathrm{~s}$, $6 \mathrm{H}) .{ }^{13} \mathrm{C}$ NMR $\left(126 \mathrm{MHz}, \mathrm{CDCl}_{3}\right) \delta 161.11,150.73,149.98,148.71$, $147.98,147.65,146.91,137.15,135.47,130.03,129.55,128.03$, $127.88,127.48,127.06,126.44,125.78,125.42,122.69,121.58$, 112.50, 40.47. HRMS (ESI) $\mathrm{m} / z$ calc $\mathrm{C}_{25} \mathrm{H}_{21} \mathrm{~N}_{4} \mathrm{O}[\mathrm{M}+\mathrm{H}]^{+}$ 393.1710; found $=393.1712$.

2,5-Dimethyl-6-(quinolin-4-yl)quinazolin-4(3H)-one, 21. Following general procedure 2, quinolin-4-ylboronic acid (25 mg; 0.144 mmol; 1.0 equiv), $\mathrm{PdCl}_{2}\left(\mathrm{PPh}_{3}\right)_{2}$ (5.1 mg; $0.00721 \mathrm{mmol} ; 0.05$ equiv), 6-bromo-2,5-dimethylquinazolin- $4(3 H)$-one $(36 \mathrm{mg} ; 0.144 \mathrm{mmol} ; 1.0$ equiv), $[0.5 \mathrm{M}] \mathrm{Na}_{2} \mathrm{CO}_{3(\mathrm{aq})}(288 \mu \mathrm{L} ; 0.144 \mathrm{mmol} ; 1.0$ equiv), and 1,4-dioxane $(2 \mathrm{~mL} ; 0.072 \mathrm{M})$ were used to yield 2,5-dimethyl-6(quinolin-4-yl)quinazolin-4(3H)-one (23 mg; $0.0764 \mathrm{mmol} ; 53 \%$ ) as a white solid. Reaction temperature: $130{ }^{\circ} \mathrm{C}$. Purification: $0-8 \%$ $\mathrm{MeOH}$ in $\mathrm{CH}_{2} \mathrm{Cl}_{2} \cdot{ }^{1} \mathrm{H}$ NMR (500 MHz, MeOD) $\delta 8.89$ (d, $J=4.4$ $\mathrm{Hz}, 1 \mathrm{H}), 8.12(\mathrm{dt}, J=8.4,0.9 \mathrm{~Hz}, 1 \mathrm{H}), 7.75(\mathrm{ddd}, J=8.4,6.7,1.5 \mathrm{~Hz}$, $1 \mathrm{H}), 7.56(\mathrm{~d}, J=8.4 \mathrm{~Hz}, 1 \mathrm{H}), 7.52(\mathrm{~d}, J=8.4 \mathrm{~Hz}, 1 \mathrm{H}), 7.48(\mathrm{ddd}, J=$ 8.1, 6.7, $1.2 \mathrm{~Hz}, 1 \mathrm{H}), 7.44-7.41(\mathrm{~m}, 1 \mathrm{H}), 7.33(\mathrm{~d}, J=4.4 \mathrm{~Hz}, 1 \mathrm{H})$, $2.51(\mathrm{~s}, 3 \mathrm{H}), 2.46(\mathrm{~s}, 3 \mathrm{H}) .{ }^{13} \mathrm{C}$ NMR $(126 \mathrm{MHz}, \mathrm{MeOD}) \delta 163.54$, $154.82,150.45,149.45,148.80,147.55,139.02,136.03,135.27$, $130.05,128.75,127.39,127.26,125.78,124.12,121.97,119.44,20.65$, 19.48. HRMS (ESI) $m / z$ calc $\mathrm{C}_{19} \mathrm{H}_{16} \mathrm{~N}_{3} \mathrm{O}[\mathrm{M}+\mathrm{H}]^{+} 302.1288$; found $=302.1282$. 
2-Ethyl-5-methyl-6-(quinolin-4-yl)quinazolin-4(3H)-one, 22. Following general procedure 2, quinolin-4-ylboronic acid $(25 \mathrm{mg}$; $0.144 \mathrm{mmol} ; 1.0$ equiv), $\mathrm{PdCl}_{2}\left(\mathrm{PPh}_{3}\right)_{2}(5.1 \mathrm{mg} ; 0.00721 \mathrm{mmol} ; 0.05$ equiv), 6-bromo-2-ethyl-5-methylquinazolin-4 $(3 \mathrm{H})$-one $(38 \mathrm{mg}$; $0.144 \mathrm{mmol} ; 1.0$ equiv), [0.5 M] $\mathrm{Na}_{2} \mathrm{CO}_{3 \text { (aq) }}(288 \mu \mathrm{L} ; 0.144 \mathrm{mmol}$; 1.0 equiv), and 1,4-dioxane $(2 \mathrm{~mL} ; 0.072 \mathrm{M})$ were used to yield 2ethyl-5-methyl-6-(quinolin-4-yl)quinazolin-4(3H)-one (28 mg; $0.0889 \mathrm{mmol} ; 62 \%)$ as a white solid. Reaction temperature: 130 ${ }^{\circ} \mathrm{C}$. Purification: $0-8 \% \mathrm{MeOH}$ in $\mathrm{CH}_{2} \mathrm{Cl}_{2} .{ }^{1} \mathrm{H}$ NMR $(500 \mathrm{MHz}$, $\left.\mathrm{CDCl}_{3}\right) \delta 11.93(\mathrm{~s}, 1 \mathrm{H}), 9.04(\mathrm{~d}, J=4.3 \mathrm{~Hz}, 1 \mathrm{H}), 8.24(\mathrm{dt}, J=8.6,0.9$ $\mathrm{Hz}, 1 \mathrm{H}$ ), 7.77 (ddd, $J=8.4,6.0,2.2 \mathrm{~Hz}, 1 \mathrm{H}), 7.69$ (dd, $J=8.3,0.7$ $\mathrm{Hz}, 1 \mathrm{H}), 7.59(\mathrm{~d}, J=8.3 \mathrm{~Hz}, 1 \mathrm{H}), 7.53-7.47(\mathrm{~m}, 2 \mathrm{H}), 7.34(\mathrm{~d}, J=$ $4.3 \mathrm{~Hz}, 1 \mathrm{H}), 2.83(\mathrm{q}, J=7.6 \mathrm{~Hz}, 2 \mathrm{H}), 2.63(\mathrm{~s}, 3 \mathrm{H}), 1.46(\mathrm{t}, J=7.6$ $\mathrm{Hz}, 3 \mathrm{H}) .{ }^{13} \mathrm{C} \mathrm{NMR}\left(126 \mathrm{MHz}, \mathrm{CDCl}_{3}\right) \delta 165.23,158.07,151.32$, $150.00,148.29,148.05,139.05,136.32,135.55,129.88,129.67$, $127.36,126.99,125.78,125.26,121.92,119.41,28.83,19.77,11.49$. HRMS (ESI) $m / z$ calc $\mathrm{C}_{20} \mathrm{H}_{18} \mathrm{~N}_{3} \mathrm{O}[\mathrm{M}+\mathrm{H}]^{+} 316.1445$; found $=$ 316.1449 .

2-Benzyl-5-methyl-6-(quinolin-4-yl)quinazolin-4(3H)-one, 23. Following general procedure 2 , quinolin-4-ylboronic acid $(12 \mathrm{mg}$; $0.0692 \mathrm{mmol} ; 1.0$ equiv), $\mathrm{PdCl}_{2}\left(\mathrm{PPh}_{3}\right)_{2}$ (5 mg; $0.00712 \mathrm{mmol} ; 0.1$ equiv), 2-benzyl-6-bromo-5-methylquinazolin-4(3H)-one $(23 \mathrm{mg}$; $0.0692 \mathrm{mmol} ; 1.0$ equiv), $[0.5 \mathrm{M}] \mathrm{Na}_{2} \mathrm{CO}_{3(\mathrm{aq})}(138 \mu \mathrm{L} ; 0.0692$ mmol; 1.0 equiv), and 1,4-dioxane $(2 \mathrm{~mL} ; 0.035 \mathrm{M})$ were used to yield 2-benzyl-5-methyl-6-(quinolin-4-yl)quinazolin-4(3H)-one (17 $\mathrm{mg} ; 0.0451 \mathrm{mmol} ; 65 \%)$ as a white solid. Reaction temperature: $150{ }^{\circ} \mathrm{C}$. Purification: $0-8 \% \mathrm{MeOH}$ in $\mathrm{CH}_{2} \mathrm{Cl}_{2} .{ }^{1} \mathrm{H}$ NMR $(500 \mathrm{MHz}$, DMSO) $\delta 12.39(\mathrm{~s}, 1 \mathrm{H}), 9.00(\mathrm{~d}, J=4.3 \mathrm{~Hz}, 1 \mathrm{H}), 8.13(\mathrm{~d}, J=8.4 \mathrm{~Hz}$, $1 \mathrm{H}), 7.80(\mathrm{ddd}, J=8.4,6.8,1.4 \mathrm{~Hz}, 1 \mathrm{H}), 7.58(\mathrm{~d}, J=0.7 \mathrm{~Hz}, 2 \mathrm{H})$, $7.56-7.52(\mathrm{~m}, 1 \mathrm{H}), 7.44-7.41(\mathrm{~m}, 3 \mathrm{H}, 14), 7.39$ (ddd, $J=8.5,1.6$, $0.7 \mathrm{~Hz}, 1 \mathrm{H}), 7.38-7.34(\mathrm{~m}, 2 \mathrm{H}), 7.30-7.25(\mathrm{~m}, 1 \mathrm{H}), 3.96(\mathrm{~s}, 2 \mathrm{H})$, $2.43(\mathrm{~s}, 3 \mathrm{H}) .{ }^{13} \mathrm{C}$ NMR $(126 \mathrm{MHz}, \mathrm{DMSO}) \delta 163.35,156.81,151.13$, $150.75,148.24,147.58,138.26,137.06,135.87,135.32,130.10$, $130.00,129.32,128.99,127.84,127.29,127.10,125.95,125.49$, $122.53,119.88,40.31,19.80$. HRMS (ESI) $m / z$ calc $\mathrm{C}_{25} \mathrm{H}_{20} \mathrm{~N}_{3} \mathrm{O}[\mathrm{M}$ $+\mathrm{H}]^{+}$378.1601; found $=378.1608$.

3,8-Dimethyl-7-(quinolin-4-yl)isoquinolin-1(2H)-one, 24. Following general procedure 2, quinolin-4-ylboronic acid $(38 \mathrm{mg}$; $0.218 \mathrm{mmol} ; 1.1$ equiv $), \mathrm{PdCl}_{2}\left(\mathrm{PPh}_{3}\right)_{2}(7.0 \mathrm{mg} ; 0.0100 \mathrm{mmol} ; 0.05$ equiv), 7-bromo-3,8-dimethyl-2H-isoquinolin-1-one (50 mg; 0.198 mmol; 1.0 equiv), $[0.5 \mathrm{M}] \mathrm{Na}_{2} \mathrm{CO}_{3(\mathrm{aq})}(397 \mu \mathrm{L} ; 0.198 \mathrm{mmol} ; 1.0$ equiv), and 1,4-dioxane ( $2 \mathrm{~mL} ; 0.099 \mathrm{M})$ were used to yield 3,8dimethyl-7-(quinolin-4-yl)isoquinolin-1(2H)-one (36 mg; 0.120 mmol; $61 \%$ yield) as a white solid. Reaction temperature: $150{ }^{\circ} \mathrm{C}$. Purification: $0-8 \% \mathrm{MeOH}$ in $\mathrm{CH}_{2} \mathrm{Cl}_{2} .{ }^{1} \mathrm{H}$ NMR $\left(500 \mathrm{MHz}, \mathrm{CDCl}_{3}\right.$ ) $\delta 10.48(\mathrm{~s}, 1 \mathrm{H}), 9.01(\mathrm{~d}, J=4.3 \mathrm{~Hz}, 1 \mathrm{H}), 8.21(\mathrm{dt}, J=8.4,0.9 \mathrm{~Hz}$, $1 \mathrm{H}), 7.75$ (ddd, $J=8.4,6.3,1.9 \mathrm{~Hz}, 1 \mathrm{H}), 7.53-7.45(\mathrm{~m}, 2 \mathrm{H}), 7.41-$ $7.40(\mathrm{~m}, 2 \mathrm{H}), 7.32(\mathrm{~d}, J=4.3 \mathrm{~Hz}, 1 \mathrm{H}), 6.32(\mathrm{~d}, J=1.3 \mathrm{~Hz}, 1 \mathrm{H}), 2.65$ $(\mathrm{s}, 3 \mathrm{H}), 2.37(\mathrm{~d}, J=1.1 \mathrm{~Hz}, 3 \mathrm{H}) .{ }^{13} \mathrm{C}$ NMR $\left(126 \mathrm{MHz}, \mathrm{CDCl}_{3}\right) \delta$ $165.32,150.08,148.72,148.37,140.67,139.68,138.01,135.92$, $133.52,129.84,129.50,127.52,126.79,126.00,123.58,122.87$, 121.94, 104.89, 20.03, 18.89. HRMS (ESI) $m / z$ calc $\mathrm{C}_{20} \mathrm{H}_{17} \mathrm{~N}_{2} \mathrm{O}[\mathrm{M}$ $+\mathrm{H}]^{+} 301.1335$, found $=301.1328$.

2-Benzyl-6-bromo-5-methylquinazolin-4(3H)-one, 26. 2Phenylacetonitrile (500 mg; $4.27 \mathrm{mmol} ; 1.0$ equiv) and hydroxylamine [ $50 \%$ in water] $(424 \mu \mathrm{L} ; 6.41 \mathrm{mmol} ; 1.5$ equiv) were stirred at $120{ }^{\circ} \mathrm{C}$ for $2 \mathrm{~h}$. The mixture was cooled to $<40{ }^{\circ} \mathrm{C}$, and 6-amino-3bromo-2-methylbenzoic acid ( $985 \mathrm{mg} ; 4.27 \mathrm{mmol} ; 1.0$ equiv) was added. The mixture was heated to $150{ }^{\circ} \mathrm{C}$, stirred for $2 \mathrm{~h}$, and cooled to $<40{ }^{\circ} \mathrm{C}$. EtOH $(20 \mathrm{~mL})$ was added to the reaction mixture which induced precipitation. The solvent was decanted three times from $\mathrm{EtOH}$, and the solid residue was dried under high vacuum. 2-Benzyl6-bromo-5-methylquinazolin-4(3H)-one (341 mg; $1.04 \mathrm{mmol}$; 24\%) was isolated at a white solid. ${ }^{1} \mathrm{H}$ NMR (500 MHz, DMSO) $\delta 12.15$ (s, $1 \mathrm{H}), 7.91(\mathrm{~d}, J=8.7 \mathrm{~Hz}, 1 \mathrm{H}), 7.38-7.34(\mathrm{~m}, 3 \mathrm{H}), 7.34-7.30(\mathrm{~m}$, $2 \mathrm{H}), 7.26-7.22(\mathrm{~m}, 1 \mathrm{H}), 3.89(\mathrm{~s}, 2 \mathrm{H}), 2.90(\mathrm{~s}, 3 \mathrm{H}) .{ }^{13} \mathrm{C}$ NMR $(126$ $\mathrm{MHz}, \mathrm{DMSO}) \delta 157.94,156.89,150.36,138.88,137.89,136.83$, 129.32, 128.96, 127.27, 127.14, 122.99, 121.14, 40.81, 21.54. HRMS (ESI) $m / z$ calc $\mathrm{C}_{16} \mathrm{H}_{14} \mathrm{BrN}_{2} \mathrm{O}[\mathrm{M}+\mathrm{H}]^{+} 329.0284$; found $=329.0284$.
3-(4-Bromo-3-methylphenyl)-2-methylacrylic acid, 27. A mixture of 4-bromo-3-methylbenzaldehyde (4.98 g, $25 \mathrm{mmol})$, methylmalonic acid $(5.90 \mathrm{~g}, 50 \mathrm{mmol})$, and piperidine $(4.94 \mathrm{~mL}$, $50 \mathrm{mmol})$ in pyridine $(30 \mathrm{~mL})$ was heated at reflux for $24 \mathrm{~h}$. The mixture was cooled and added to a mixture of ice (ca. $125 \mathrm{~g}$ ) and conc. $\mathrm{HCl}(70 \mathrm{~mL})$. The precipitate formed was filtered off and washed with cold water. The product was dried under vacuum to afford 3-(4-bromo-3-methylphenyl)-2-methylacrylic acid (6.1 g, $64.3 \%$ yield $)$ as a waxy solid. ${ }^{1} \mathrm{H}$ NMR $\left(500 \mathrm{MHz}, \mathrm{CDCl}_{3}\right) \delta 11.77$ $(\mathrm{s}, 1 \mathrm{H}), 7.74(\mathrm{~d}, J=1.6 \mathrm{~Hz}, 1 \mathrm{H}), 7.58(\mathrm{~d}, J=8.2 \mathrm{~Hz}, 1 \mathrm{H}), 7.30(\mathrm{~d}, J=$ $2.1 \mathrm{~Hz}, 1 \mathrm{H}), 7.14(\mathrm{dd}, J=8.3,2.2 \mathrm{~Hz}, 1 \mathrm{H}), 2.45(\mathrm{~s}, 3 \mathrm{H}), 2.14(\mathrm{~d}, J=$ $1.6 \mathrm{~Hz}, 3 \mathrm{H}) .{ }^{13} \mathrm{C} \mathrm{NMR}\left(126 \mathrm{MHz}, \mathrm{CDCl}_{3}\right) \delta 173.72,139.99,138.10$, $134.72,132.44,132.11,128.49,127.94,125.48,22.98,13.79$.

3-(4-Bromo-3-methylphenyl)-2-methylacryloyl azide, 28. To a suspension of 3-(4-bromo-3-methylphenyl)-2-methylacrylic acid $\left(4.80 ;, 18.8 \mathrm{mmol} ; 1.0\right.$ equiv) in acetone $(100 \mathrm{~mL})$ at $0{ }^{\circ} \mathrm{C}$ was added triethylamine ( $3.41 \mathrm{~mL} ; 24.5 \mathrm{mmol} ; 1.3$ equiv). A clear solution was formed. Then, ethyl chloroformate $(2.16 \mathrm{~mL} ; 22.6$ mmol; 1.2 equiv) was added, and a thick suspension was formed. The suspension was allowed to warm to room temperature. After $2 \mathrm{~h}$, sodium azide ( $1.83 \mathrm{~g} ; 28.2 \mathrm{mmol} ; 1.5$ equiv) in water $(15 \mathrm{~mL})$ was added dropwise, and the suspension was stirred for a further $2 \mathrm{~h}$. The suspension was cooled down and diluted with water $(50 \mathrm{~mL})$. Ethyl acetate $(200 \mathrm{~mL})$ was added, the layers were separated, and the aqueous layer was extracted with more ethyl acetate $(2 \times 50 \mathrm{~mL})$. The organic were washed with sat. aq. $\mathrm{NaHCO}_{3}(2 \times 50 \mathrm{~mL})$, dried $\left(\mathrm{MgSO}_{4}\right)$, filtered and concentrated (without heating) to yield the product as a white solid (5.1 g, 97\% yield). ${ }^{1} \mathrm{H}$ NMR $(500 \mathrm{MHz}$, $\left.\mathrm{CDCl}_{3}\right) \delta 7.65(\mathrm{~d}, J=1.5 \mathrm{~Hz}, 1 \mathrm{H}), 7.58(\mathrm{~d}, J=8.3 \mathrm{~Hz}, 1 \mathrm{H}), 7.29-$ $7.28(\mathrm{~m}, 1 \mathrm{H}), 7.12(\mathrm{dd}, J=8.3,2.3 \mathrm{~Hz}, 1 \mathrm{H}), 2.44(\mathrm{~s}, 3 \mathrm{H}), 2.12(\mathrm{~d}, J=$ $1.4 \mathrm{~Hz}, 3 \mathrm{H}) .{ }^{13} \mathrm{C}$ NMR $\left(126 \mathrm{MHz}, \mathrm{CDCl}_{3}\right) \delta 174.36,139.94,138.23$, $134.36,132.54,132.22,129.99,128.59,125.92,22.98,13.87$.

7-Bromo-3,8-dimethyl-2H-isoquinolin-1-one, 29 and 7bromo-3,6-dimethyl-2H-isoquinolin-1-one, 30. A suspension of 3-(4-bromo-3-methylphenyl)-2-methylacryloyl azide (4.76 g; 17.0 mmol; 1.0 equiv) in 1,2-dichlorobenzene $(70 \mathrm{~mL})$ was heated to 140 ${ }^{\circ} \mathrm{C}$ for $1 \mathrm{~h}$. Then, iodine ( $431.5 \mathrm{mg} ; 1.7 \mathrm{mmol}$; 0.1 equiv) was added, and the mixture was heated at reflux $\left(\mathrm{ca} .180{ }^{\circ} \mathrm{C}\right.$ ) for $6 \mathrm{~h}$ and cooled to room temperature. The solution was stirred overnight at room temperature, and the solid formed was filtered and washed with 20 $\mathrm{mL}$ of cyclohexane. The solid was dried for $1 \mathrm{~h}$ at $50{ }^{\circ} \mathrm{C}$ and 20 Torr to give a mixture of 29 and $\mathbf{3 0}(2.16 \mathrm{~g} ; 50 \%$ yield $)$ in a ratio $3: 2\left({ }^{1} \mathrm{H}\right.$ NMR). Normal phase flash chromatography of the mixture $(0-25 \%$ EtOAc in cyclohexane) gave $116 \mathrm{mg}$ of pure $29,660 \mathrm{mg}$ of mixture and $260 \mathrm{mg}$ of pure 30. For 29: ${ }^{1} \mathrm{H}$ NMR (500 MHz, DMSO) $\delta 11.24$ $(\mathrm{s}, 1 \mathrm{H}), 7.77(\mathrm{~d}, J=8.5 \mathrm{~Hz}, 1 \mathrm{H}), 7.29(\mathrm{~d}, J=8.5 \mathrm{~Hz}, 1 \mathrm{H}), 6.27(\mathrm{dd}, J$ $=2.0,1.1 \mathrm{~Hz}, 1 \mathrm{H}), 2.95(\mathrm{~s}, 3 \mathrm{H}), 2.16(\mathrm{~d}, J=1.1 \mathrm{~Hz}, 3 \mathrm{H}) .{ }^{13} \mathrm{C} \mathrm{NMR}$ (126 MHz, DMSO) $\delta 163.21,140.03,139.80,139.40,136.12,125.89$, $124.19,123.08,103.48,21.76,18.77$. HRMS (ESI) $\mathrm{m} / z$ calc for $\mathrm{C}_{11} \mathrm{H}_{11}{ }^{79} \mathrm{BrNO}[\mathrm{M}+\mathrm{H}]^{+} 252.0019$, found $=252.0014$. For $30:{ }^{1} \mathrm{H}$ NMR (DMSO, $500 \mathrm{MHz}) \delta 11.30(\mathrm{br}-\mathrm{s}, 1 \mathrm{H}), 8.20(\mathrm{~s}, 1 \mathrm{H}), 7.51(\mathrm{a}$, $1 \mathrm{H}), 6.26(\mathrm{~s}, 1 \mathrm{H}), 2.43(\mathrm{~s}, 3 \mathrm{H}), 2.18(\mathrm{~s}, 3 \mathrm{H}) .{ }^{13} \mathrm{C}$ NMR (DMSO, 126 $\mathrm{MHz}) \delta 161.2,141.8,139.5,137.6,129.6,127.4,123.8,121.1,102.0$, 22.8, 18.8. HRMS (ESI) $\mathrm{m} / z$ calc for $\mathrm{C}_{11} \mathrm{H}_{11}{ }^{79} \mathrm{BrNO}[\mathrm{M}+\mathrm{H}]^{+}$ 252.0019 , found $=252.0015$.

\section{ASSOCIATED CONTENT}

S Supporting Information

The Supporting Information is available free of charge on the ACS Publications website at DOI: 10.1021/acs.jmedchem. 8 b00782.

Molecular formula strings (CSV)

Experimental and characterization details for all new compounds, assay data, crystallographic data and NMR spectra (PDF)

\section{Accession Codes}

The PDB ID codes for 11, 16, and 21 bound to ALK2 are 6GI6, 6GIN and 6GIP, respectively. Authors will release the 
atomic coordinates and experimental data upon article publication.

\section{AUTHOR INFORMATION}

\section{Corresponding Author}

*E-mail: Swen.Hoelder@icr.ac.uk. Phone: +44 (0) 2087224353.

\section{ORCID}

Santiago Vázquez: 0000-0002-9296-6026

Swen Hoelder: 0000-0001-8636-1488

\section{Notes}

The authors declare no competing financial interest.

\section{ACKNOWLEDGMENTS}

L.H. and J.M. were funded by Wellcome Trust [Grant Number $090171 / \mathrm{Z} / 09 / \mathrm{Z}]$. We acknowledge NHS funding to the NIHR Biomedical Research Centre and funding from Cancer Research UK [Grant Number C309/A11566]. S.V. thanks the Spanish Ministerio de Educación, Cultura y Deporte for a "Salvador de Madariaga" mobility grant. C.J. and D.C. acknowledge support from Children with Cancer UK, Abbie's Army and the DIPG Collaborative, the Lyla Nsouli Foundation and Lucas' Legacy. The authors thank Diamond Light Source for beamtime (proposal mx10619), as well as the staff of beamlines I02, I03, and I04 for assistance with crystal testing and data collection. The SGC is a registered charity (Number 1097737) that receives funds from AbbVie, Bayer Pharma AG, Boehringer Ingelheim, Canada Foundation for Innovation, Eshelman Institute for Innovation, Genome Canada, Innovative Medicines Initiative (EU/EFPIA) [ULTRA-DD Grant No. 115766], Janssen, MSD, Merck KGaA., Novartis Pharma AG, Ontario Ministry of Economic Development and Innovation, Pfizer, São Paulo Research Foundation-FAPESP, Takeda, and Wellcome Trust [106169/ZZ14/Z].

\section{ABBREVIATIONS USED}

ALK, activin receptor-like kinase; DIPG, diffuse intrinsic pontine glioma; FKBP12, FK506 binding protein 12; SMAD, small mothers against decapantaplegic; FOP, fibrodysplasia ossificans progressiva; RAF, rapidly accelerated fibrosarcoma; PDGFR, platelet-derived growth factor receptor; BMP, bone morphogenic protein; ID1, inhibitor of DNA binding 1

\section{REFERENCES}

(1) Vogt, J.; Traynor, R.; Sapkota, G. P. The specificities of small molecule inhibitors of the TGFß and BMP pathways. Cell. Signalling 2011, 23 (11), 1831-1842.

(2) Chaikuad, A.; Alfano, I.; Kerr, G.; Sanvitale, C. E.; Boergermann, J. H.; Triffitt, J. T.; Von Delft, F.; Knapp, S.; Knaus, P.; Bullock, A. N. Structure of the bone morphogenetic protein receptor ALK2 and implications for fibrodysplasia ossificans progressiva. J. Biol. Chem. 2012, 287 (44), 36990-36998.

(3) Hatsell, S. J.; Idone, V.; Wolken, D. M. A.; Huang, L.; Kim, H. J.; Wang, L.; Wen, X.; Nannuru, K. C.; Jimenez, J.; Xie, L.; Das, N.; Makhoul, G.; Chernomorsky, R.; D’Ambrosio, D.; Corpina, R. A.; Schoenherr, C. J.; Feeley, K.; Yu, P. B.; Yancopoulos, G. D.; Murphy, A. J.; Economides, A. N. ACVR1R206H receptor mutation causes fibrodysplasia ossificans progressiva by imparting responsiveness to activin A. Sci. Transl. Med. 2015, 7 (303), 303ra137.

(4) Taylor, K. R.; Vinci, M.; Bullock, A. N.; Jones, C. ACVR1 mutations in DIPG: lessons learned from FOP. Cancer Res. 2014, 74 (17), 4565-4570.

(5) Warren, K. E. Diffuse intrinsic pontine glioma: poised for progress. Front. Oncol. 2012, 2 (December), 205.
(6) Yu, P. B.; Hong, C. C.; Sachidanandan, C.; Babitt, J. L.; Deng, D. Y.; Hoyng, S. a; Lin, H. Y.; Bloch, K. D.; Peterson, R. T. Dorsomorphin inhibits BMP signals required for embryogenesis and iron metabolism. Nat. Chem. Biol. 2008, 4 (1), 33-41.

(7) Cuny, G. D.; Yu, P. B.; Laha, J. K.; Xing, X.; Liu, J.-F.; Lai, C. S.; Deng, D. Y.; Sachidanandan, C.; Bloch, K. D.; Peterson, R. T. Structure-activity relationship study of bone morphogenetic protein (BMP) signaling inhibitors. Bioorg. Med. Chem. Lett. 2008, 18 (15), 4388-4392.

(8) Mohedas, A. H.; Xing, X.; Armstrong, K. a.; Bullock, A. N.; Cuny, G. D.; Yu, P. B. Development of an ALK2-biased BMP type I receptor kinase inhibitor. ACS Chem. Biol. 2013, 8 (6), 1291-1302.

(9) Engers, D. W.; Frist, A. Y.; Lindsley, C. W.; Hong, C. C.; Hopkins, C. R. Synthesis and structure-activity relationships of a novel and selective bone morphogenetic protein receptor (BMP) inhibitor derived from the pyrazolo[1.5-a]pyrimidine scaffold of dorsomorphin: the discovery of ML347 as an ALK2 versus ALK3 selective MLPCN probe. Bioorg. Med. Chem. Lett. 2013, 23 (11), 3248-3252.

(10) (i) Vogt, J.; Traynor, R.; Sapkota, G. P. The specificities of small molecule inhibitors of the TGFß and BMP pathways. Cell. Signalling 2011, 23 (11), 1831-1842. (ii) Sinha, S.; Mundy, C.; Bechtold, T.; Sgariglia, F.; Ibrahim, M. M.; Billings, P. C.; Carroll, K.; Koyama, E.; Jones, K. B.; Pacifici, M. Unsuspected osteochondromalike outgrowths in the cranial base of Hereditary Multiple Exostoses patients and modeling and treatment with a BMP antagonist in mice. PLoS Genet. 2017, 13 (4), e1006742.

(11) Sanvitale, C. E.; Kerr, G.; Chaikuad, A.; Ramel, M.-C.; Mohedas, A. H.; Reichert, S.; Wang, Y.; Triffitt, J. T.; Cuny, G. D.; Yu, P. B.; Hill, C. S.; Bullock, A. N. A new class of small molecule inhibitor of BMP signaling. PLoS One 2013, 8 (4), e62721.

(12) Mohedas, A.; Wang, Y.; Sanvitale, C. E.; Canning, P.; Choi, S.; Xing, X.; Bullock, A. N.; Cuny, G. D.; Yu, P. B. Structure-activity relationship of 3,5-diaryl-2-aminopyridine ALK2 inhibitors reveals unaltered binding affinity for fibrodysplasia ossificans progressiva causing mutants. J. Med. Chem. 2014, 57, 7900-7915.

(13) Boys, M. L.; Bian, F.; Kramer, J. B.; Chio, C. L.; Ren, X. D.; Chen, H.; Barrett, S. D.; Sexton, K. E.; Iula, D. M.; Filzen, G. F.; Nguyen, M. N.; Angell, P.; Downs, V. L.; Wang, Z.; Raheja, N.; Ellsworth, E. L.; Fakhoury, S.; Bratton, L. D.; Keller, P. R.; Gowan, R.; Drummond, E. M.; Maiti, S. N.; Hena, M. a.; Lu, L.; McConnell, P.; Knafels, J. D.; Thanabal, V.; Sun, F.; Alessi, D.; McCarthy, A.; Zhang, E.; Finzel, B. C.; Patel, S.; Ciotti, S. M.; Eisma, R.; Payne, N. a.; Gilbertsen, R. B.; Kostlan, C. R.; Pocalyko, D. J.; Lala, D. S. Discovery of a series of 2-(1H-pyrazol-1-yl)pyridines as ALK5 inhibitors with potential utility in the prevention of dermal scarring. Bioorg. Med. Chem. Lett. 2012, 22 (10), 3392-3397.

(14) Gellibert, F.; Woolven, J.; Fouchet, M.-H.; Mathews, N.; Goodland, H.; Lovegrove, V.; Laroze, A.; Nguyen, V.-L.; Sautet, S.; Wang, R.; Janson, C.; Smith, W.; Krysa, G.; Boullay, V.; De Gouville, A.-C.; Huet, S.; Hartley, D. Identification of 1,5-naphthyridine derivatives as a novel series of potent and selective TGF- $\beta$ type I receptor inhibitors. J. Med. Chem. 2004, 47, 4494-4506.

(15) Hitchcock, S. A.; Pennington, L. D. Structure-brain exposure relationships. J. Med. Chem. 2006, 49 (26), 7559-7583.

(16) Larrivée, B.; Prahst, C.; Gordon, E.; del Toro, R.; Mathivet, T.; Duarte, A.; Simons, M.; Eichmann, A. ALK1 signaling inhibits angiogenesis by cooperating with the Notch pathway. Dev. Cell 2012, 22, 489-500.

(17) Adib, M.; Ansari, S.; Mohammadi, A.; Bijanzadeh, H. R. A novel, one-pot, solvent-, and catalyst-free synthesis of 2-aryl/alkyl-4 (3H)-quinazolinones. Tetrahedron Lett. 2010, 51 (1), 30-32.

(18) Gensler, W. J.; Berman, E. Decarboxylative condensation. $\alpha$ alkylcinnamic acids from aromatic aldehydes and alkylmalonic acids. $J$. Am. Chem. Soc. 1958, 80, 4949-4954. 